OPEN ACCESS

Edited by:

Yuqing Wang,

University of Hawaii at Manoa,

United States

Reviewed by:

Yong Han,

Sun Yat-Sen University, China

Eric Hendricks,

National Center for Atmospheric

Research (UCAR), United States

Zhang $L i$,

Chinese Academy of Sciences (CAS),

China

*Correspondence: Xiangjun Tian

tianxj@itpcas.ac.cn

Specialty section:

This article was submitted to

Atmospheric Science,

a section of the journal

Frontiers in Earth Science

Received: 31 March 2021

Accepted: 21 June 2021

Published: 14 July 2021

Citation:

Jin Z, Tian X, Duan M and Han R (2021) An Efficient Algorithm for Retrieving

$\mathrm{CO}_{2}$ in the Atmosphere From

Hyperspectral Measurements of Satellites: Application of NLS-4DVar

Data Assimilation Method.

Front. Earth Sci. 9:688542.

doi: 10.3389/feart.2021.688542

\section{An Efficient Algorithm for Retrieving $\mathrm{CO}_{2}$ in the Atmosphere From Hyperspectral Measurements of Satellites: Application of NLS-4DVar Data Assimilation Method}

\author{
Zhe Jin ${ }^{1,2}$, Xiangjun Tian ${ }^{3,2,4 *}$, Minzheng Duan ${ }^{5,2}$ and Rui Han ${ }^{1,2}$
}

${ }^{1}$ International Center for Climate and Environment Sciences, Institute of Atmospheric Physics, Chinese Academy of Sciences, Beijing, China, ${ }^{2}$ College of Earth and Planetary Sciences, University of Chinese Academy of Sciences, Beijing, China, ${ }^{3}$ National Tibetan Plateau Data Center, Key Laboratory of Tibetan Environment Changes and Land Surface Processes, Institute of Tibetan Plateau Research, Chinese Academy of Sciences, Beijing, China, ${ }^{4}$ Collaborative Innovation Center on Forecast and Evaluation of Meteorological Disasters, Nanjing University of Information Science and Technology, Nanjing, China, ${ }^{5}$ Key Laboratory for Middle Atmosphere and Global Environment Observation, Institute of Atmospheric Physics, Chinese Academy of Sciences, Beijing, China

A novel and efficient inverse method, named Nonlinear least squares four-dimensional variational data Assimilation (NLS-4DVar)-based $\mathrm{CO}_{2}$ Retrieval Algorithm (NARA), is proposed for retrieving atmospheric $\mathrm{CO}_{2}$ from the satellite hyperspectral measurements, in which the NLS-4DVar method is used as the optimization method. As the NLS-4DVar method works independently of the tangent linear model and adjoint model, the time-consuming calculation of the weighting function matrix is unnecessary, and the computation complexity is tremendously reduced while maintaining the retrieval accuracy. This is extremely important for space-based $\mathrm{CO}_{2}$ retrievals with large data volumes. Observing system simulation experiments (OSSEs) over four different sites around the world showed that the NARA algorithm could retrieve $X_{\mathrm{CO} 2}$ and $\mathrm{CO}_{2}$ profiles effectively. To further evaluate the NARA algorithm, it was used for real $\mathrm{CO}_{2}$ retrievals from target-mode observations of Orbiting Carbon Observatory-2 (OCO-2) over Lamont, Oklahoma, and Darwin, Australia. The results were compared with that of ground measurements of Total Carbon Column Observing Network (TCCON). The mean difference of $X_{\mathrm{CO} 2}$ between NARA and TCCON over Lamont, from 180 observations, was $-0.15 \mathrm{ppmv}$ with a standard deviation (SD) of $0.76 \mathrm{ppmv}$. Over Darwin, the mean difference, from 180 observations (90 points over land and 90 points over the ocean), is -0.17 ppmv (SD: 1.26 ppmv). The preliminary results showed that the efficient NLS4DVar-based algorithm could provide great help for satellite remote sensing of $\mathrm{CO}_{2}$, and it may be used as an operational procedure after further and extensive evaluations.

Keywords: Atmospheric $\mathrm{CO}_{2}, \mathrm{XCO}_{2}$, retrieval algorithm, NLS-4DVar, satellite observations, OCO-2 


\section{INTRODUCTION}

The concentration of $\mathrm{CO}_{2}$ in the atmosphere has continued to increase since the Industrial Revolution, which has had a significant impact on the global climate (Cox et al., 2000; Le Quéré et al., 2016). The formulation of climate policy and control of the future climate require a more accurate and comprehensive understanding of the global carbon cycle (Dilling et al., 2003). Current ground-based and aircraft observations could provide help in modelling and understanding global sources and sinks of $\mathrm{CO}_{2}$ (Wunch et al., 2011); however, the insufficient number and sparse spatial coverage make it difficult to obtain accurate $\mathrm{CO}_{2}$ fluxes on regional scales (Baker et al., 2010; O’Dell et al., 2012).

To acquire $\mathrm{CO}_{2}$ fluxes with high spatial and temporal resolutions to supplement the deficiencies of ground-based and aircraft observations, efforts have been made to retrieve the column-averaged dry air mole fraction of atmospheric $\mathrm{CO}_{2}\left(X_{\mathrm{CO} 2}\right)$ from satellite observations (Rayner and O'Brien, 2001; Miller et al., 2007). Data retrieved from the thermal infrared spectrograph are able to provide good information of $\mathrm{CO}_{2}$ in the mid-troposphere (Chédin et al., 2003; Crevoisier et al., 2009; Kulawik et al., 2010), but the measurements are less sensitive to near surface $\mathrm{CO}_{2}$ variations. Therefore measurements in Nearinfrared (NIR)- and short-wave infrared (SWIR)-band are proposed, such as the SCanning Imaging Absorption spectroMeter for Atmospheric CHartographY (SCIAMACHY) (Buchwitz et al., 2005; Reuter et al., 2011), which is a midresolution spectrometer. The first dedicated greenhouse gas satellite Greenhouse gases Observing SATellite (GOSAT) and its successor GOSAT-2, with ultra-high spectral resolution in NIR and SWIR bands, were launched into space by Japan Erospace Exploration Agency (JAXA) separately in 2008 (Yokota et al., 2009) and 2018 (Nakajima et al., 2012). Similar specific satellites such as Orbiting Carbon Observatory-2 (OCO-2) (Crisp et al., 2004) and OCO-3 (Eldering et al., 2019) are launched into space separately in 2014 and 2019. China also launched its first satellite, TanSat, for Carbon dioxide measurements in 2016 (Yang et al., 2018). These measurements from space could provide spatial map of atmospheric $\mathrm{CO}_{2}$ and its variation both on regional and global scales (Jiang and Yung, 2019).

A variety of algorithms have been developed for retrievals of $\mathrm{CO}_{2}$ from NIR and SWIR spectra, including the Differential Optical Absorption Spectroscopy (DOAS) approach for SCIAMACHY (Buchwitz et al., 2000; Honninger et al., 2004; Reuter et al., 2010), the National Institute for Environment Studies (NIES) algorithm developed for GOSAT measurements (Yoshida et al., 2011), the Atmospheric $\mathrm{CO}_{2}$ Observations from Space (ACOS) algorithm applied to GOSAT and OCO-2 measurements (Crisp et al., 2012; O’Dell et al., 2012; O'Dell et al., 2018), the University of Leicester Full Physics (UoL-FP) algorithm (Boesch et al., 2011), the RemoTeC algorithm developed by SORN Netherlands Institute for Space Research and Deutsches Zentrum für Luft-und Raumfahrt e.V. (DLR) (Hasekamp and Butz, 2008; Butz et al., 2011; Guerlet et al., 2013) and the ensemble median (EEMA) algorithm (Reuter et al., 2013).

Until now, it is still a challenge to retrieve accurate $\mathrm{CO}_{2}$ concentrations and its vertical profiles from satellite measurements (Yue et al., 2016), some of them can only produce reasonable results under very clear skies. This is due to limitations of parameterization and simplification in the algorithm, i.e., first guess of $\mathrm{CO}_{2}$ profile, atmospheric parameters and their vertical distributions, and simplification of the weighting function matrix calculation owing to timeconsuming burden. In this paper, a novel algorithm, NLS4DVar-based $\mathrm{CO}_{2}$ Retrieval Algorithm (NARA), is proposed. The NLS-4DVar method rewrites the cost function as a nonlinear least squares problem and solves it iteratively using the GaussNewton method. In the iterative process, the a priori covariance matrix is not a fixed one but constantly updated. Moreover, the calculations of the weighting function matrix and its transposition are avoided through simple mathematical transformations, which greatly reduces programming difficulty and computational complexity while maintaining the retrieval accuracy. This is particularly important for space-based $\mathrm{CO}_{2}$ retrievals considering the huge number of satellite measurements.

The rest of this article is organized as follows. Sect. 2 introduces the NARA algorithm in detail, including the forward and inverse models. Sect. 3 evaluates the NARA algorithm in terms of $X_{\mathrm{CO} 2}$ and the $\mathrm{CO}_{2}$ profile through observing system simulation experiments (OSSEs). Sect. 4 describes real-data retrievals using OCO-2 observations and comparisons between NARA retrieved $X_{\mathrm{CO} 2}$ and coincident TCCON measurements. Finally, Sect. 5 discusses and concludes the paper.

\section{DESCRIPTION OF THE NLS-4DVAR-BASED $\mathrm{CO}_{2}$ RETRIEVAL ALGORITHM}

The NARA retrieval algorithm obtains the optimal state vector under the joint constraints of satellite measurements and prior information. The state vector contains the $\mathrm{CO}_{2}$ profile and several parameters to which the spectra are sensitive. The optimal column-averaged $\mathrm{CO}_{2}$ is calculated according to the $\mathrm{CO}_{2}$ profile. The NARA algorithm can be applied to any greenhouse gas satellites, but requires some specific modifications according to the satellite instruments. At present, we use information and observations from OCO-2 satellite to make preliminary evaluations of the NARA algorithm. The OCO-2 observations of the reflected sunlight spectra in three bands: $\mathrm{O}_{2} \mathrm{~A}$ band at $0.76 \mu \mathrm{m}$, weak $\mathrm{CO}_{2}$ band at $1.61 \mu \mathrm{m}$, and strong $\mathrm{CO}_{2}$ band at $2.06 \mu \mathrm{m}$ are used for retrievals (O'Dell et al., 2018). NARA algorithm include data preparation, $X_{\mathrm{CO} 2}$ retrieval and bias correction. A flow chart of the NARA algorithm is shown in Figure 1.

\section{Data Input and Pre-screening}

The input data of the algorithm include the Level $1 \mathrm{~B}$ product of satellite measurements and meteorological data interpolated to the observation points. The Level $1 \mathrm{~B}$ product includes the calibrated radiances for three spectral bands and geolocation information. The pixels with low signal-to-noise ratio and those contaminated by clouds and aerosols are filtered out (Taylor et al., 2016). The meteorological data include surface pressure, water vapor profile, temperature profile, and surface wind speed, which are from gridded GEOS5-FP-IT (Goddard Earth Observing System, 


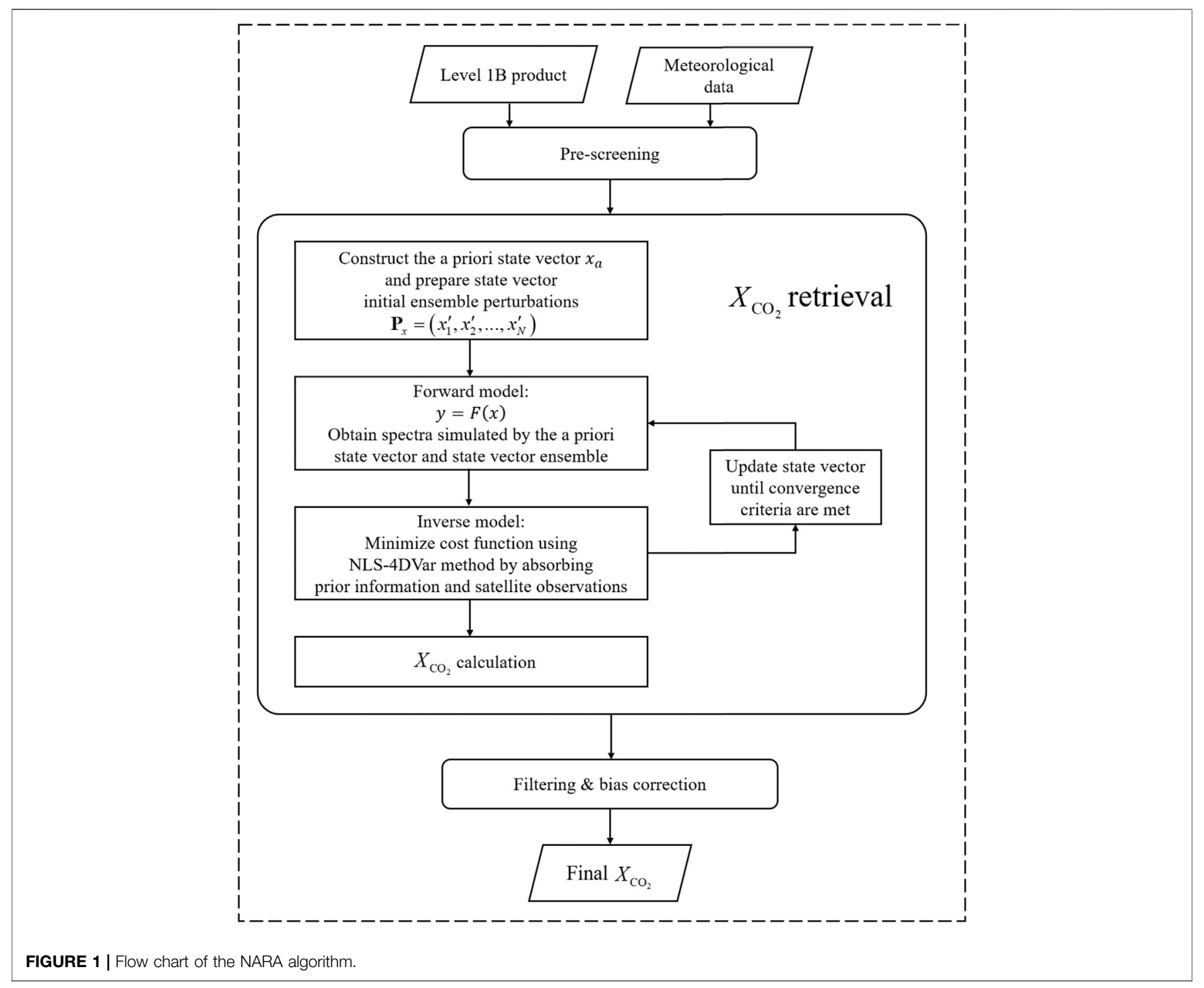

Version 5, Forward Processing for Instrument Teams) reanalysis and interpolated to the observation location.

\section{2. $X_{\mathrm{CO} 2}$ Retrieval}

The $X_{\mathrm{CO} 2}$ retrieval is the core of the algorithm. $X_{\mathrm{CO} 2}$ is the column-averaged dry air mole fraction of atmospheric $\mathrm{CO}_{2}$, and the unit is part per million (ppm). The a priori state vector from the input data, as well as the initial ensemble of the state vector, are constructed. They are then input into the forward model to obtain simulated spectra. This information and satellite observations are input into the inverse model, and the optimal estimate of the state vector is obtained through the NLS-4DVar method. $X_{\mathrm{CO} 2}$ is then calculated according to the $\mathrm{CO}_{2}$ profile in the state vector.

\section{Bias Correction}

Currently all space-borne $X_{\mathrm{CO} 2}$ retrievals have systematic biases, mainly due to uncertainty in spectroscopy, limitations in the information provided by the observations, imperfect modelling of the atmosphere and surface, as well as uncertainty in instruments. Therefore, bias correction is necessary for the retrieved $X_{\mathrm{CO} 2}$ (Schneising et al., 2012; Guerlet et al., 2013; Crisp et al., 2017). The bias correction procedure of NARA algorithm adopted from OCO-2 consists of three main parts: first, correct the parametric biases that is caused by the spurious correlation of the retrieved $X_{\mathrm{CO} 2}$ with other retrieval parameters; second, correct the footprintdependent biases that are truly instrument-related; finally, apply a global scaling to remove the remaining biases (O'Dell et al., 2018).

\section{Forward Model}

The parameters to be optimized in the forward model constitute the state vector $\boldsymbol{x}$. The reflected sunlight received by all channels in the three bands constitutes the observation vector $y$. The simulation of observation from a state vector can be expressed by the following formula:

$$
y=F(\boldsymbol{x}, \boldsymbol{b})+\boldsymbol{\varepsilon},
$$


TABLE 1 | Standard deviations of normal distributions when generating ensembles of initial perturbations for parameters in the state vector excluding the $\mathrm{CO}_{2}$ profile.

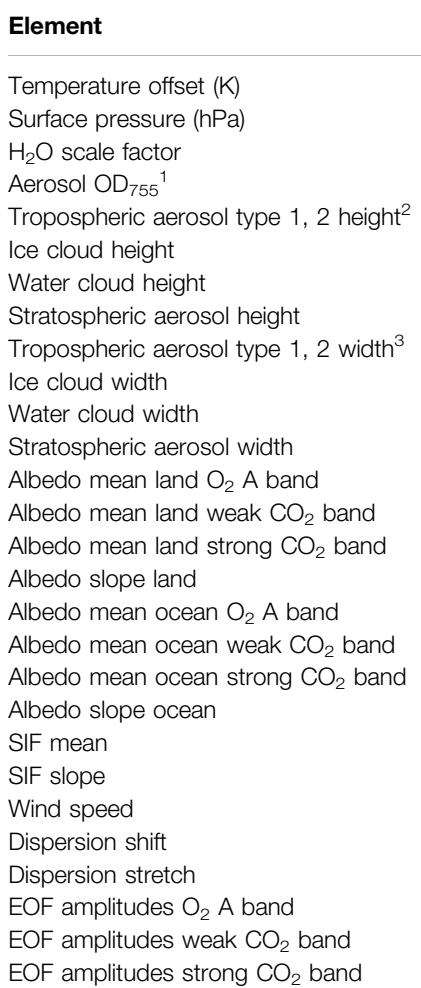

\begin{tabular}{|c|c|}
\hline No. of elements & Sigma \\
\hline 1 & $0.5 \mathrm{~K}$ \\
\hline 1 & $2 \mathrm{hPa}$ \\
\hline 1 & 0.1 \\
\hline 1 per type & 0.5 \\
\hline 2 & 0.1 \\
\hline 1 & 0.1 \\
\hline 1 & 0.2 \\
\hline 1 & $1 e-7$ \\
\hline 2 & 0.01 \\
\hline 1 & 0.0005 \\
\hline 1 & 0.0003 \\
\hline 1 & 0.001 \\
\hline 1 & 0.4 \\
\hline 1 & 0.2 \\
\hline 1 & 0.2 \\
\hline 1 per band & 0.0005 \\
\hline 1 & 0.01 \\
\hline 1 & 0.01 \\
\hline 1 & 0.001 \\
\hline 1 per band & $2 e-5$ \\
\hline 1 & $1 e 17$ \\
\hline 1 & $3 e-8$ \\
\hline 1 & $2 \mathrm{~m} / \mathrm{s}$ \\
\hline 1 per band & $5 e-7$ \\
\hline 1 per band & $1 e-8$ \\
\hline 3 & $0.01,0.005,0.005$ \\
\hline 3 & $0.005,0.005,0.005$ \\
\hline 3 & $0.003,0.002,0.005$ \\
\hline
\end{tabular}

${ }^{1}$ Aerosol optical depth at $755 \mathrm{~nm}$.

${ }^{2}$ Location of the peak height of the Gaussian vertical profile.

${ }^{3} 1$-sigma width of the Gaussian vertical profile.

where $F$ is the forward model, $\boldsymbol{b}$ is a set of fixed input parameters, and $\varepsilon$ is the error in both the instrument and forward model. The forward model uses the Linearized Discrete Ordinate Radiative Transfer (LIDORT) model (Spurr et al., 2001; Spurr and Natraj, 2011) as the radiative transfer model and some parameters about solar, surface and instrument provided by the ACOS algorithm (O'Dell et al., 2018). The state vector includes the $\mathrm{CO}_{2}$ profile defined at a set of 20 atmospheric pressure levels, a temperature profile offset, surface pressure, a water vapor profile multiplier, aerosol parameters, surface albedo parameters, instrument correction parameters, spectrum correction parameters, and solar-induced fluorescence (SIF) parameters, which are listed in Table 1 in detail. The atmosphere with few clouds and aerosols can retrieve more accurate $X_{\mathrm{CO} 2}$ than other conditions because of atmospheric scattering. To account for scattering effects of thin clouds and aerosols, the retrieval solves simultaneously for amounts and Gaussian vertical profiles of five different kinds of scatterers with fixed optical properties: a water cloud type, an ice cloud type, two fixed aerosol types, and an upper tropospheric/lower stratospheric sulfate aerosol type. The two fixed aerosol types are chosen from co-located GEOS-5 FP-IT aerosols. They are the types that form the highest and second highest fraction of the AOD (aerosol optical depth) at $755 \mathrm{~nm}$ for a co-located GEOS-5 grid cell for a given sounding.
The prior value of the state vector is calculated by the ACOS algorithm (O'Dell et al., 2012; O’Dell et al., 2018). The vertical coordinate uses a simple sigma coordinate system, that is $P_{\text {levels }}=P_{\text {surf }} \cdot \boldsymbol{a}, \boldsymbol{a}=\left(0.0001, \frac{1}{19}, \frac{2}{19}, \ldots, \frac{18}{19}, 1\right)^{T}$, where $P_{\text {levels }}$ is the 20 vertical pressure levels, $P_{\text {surf }}$ is the surface pressure, and $\boldsymbol{a}$ is a fixed coefficient array. For $P_{\text {surf }}=1000 \mathrm{hPa}$, the pressure width of all the layers (except the top layer) is $52.63 \mathrm{~h} \mathrm{~Pa}$; for the top layer it is $52.53 \mathrm{hPa}$. The typical model lid is roughly $0.1 \mathrm{hPa}$. Assume that the tropopause pressure is $200 \mathrm{hPa}$ (Hoinka, 1998), then the ratio of the tropopause pressure to the surface pressure is 0.2 . According to the $\boldsymbol{a}$ coefficient, the $\mathrm{CO}_{2}$ profile mainly describes the troposphere $\mathrm{CO}_{2}$ concentration, apart from about the first four levels describing the $\mathrm{CO}_{2}$ concentration above the troposphere.

\section{Inverse Model}

The inverse model is used to obtain the minimum value of the following cost function through the optimization algorithm:

$$
\chi^{2}(\boldsymbol{x})=\left(\boldsymbol{x}-\boldsymbol{x}_{\mathbf{a}}\right)^{\mathrm{T}} \mathbf{S}_{\mathbf{a}}^{-1}\left(\boldsymbol{x}-\boldsymbol{x}_{\mathbf{a}}\right)+[F(\boldsymbol{x})-\mathbf{y}]^{\mathrm{T}} \mathbf{S}_{\boldsymbol{\varepsilon}}^{-1}[F(\boldsymbol{x})-\boldsymbol{y}]
$$

where $\boldsymbol{x}_{\mathbf{a}} \in \mathbb{R}^{n_{x}}$ ( $n_{x}$ is the dimension of the state vector) is the a priori state vector, $\mathbf{S}_{\mathbf{a}}$ is the a priori covariance matrix, $F(\boldsymbol{x})$ is the spectra simulated by the state vector, $\boldsymbol{S}_{\boldsymbol{\varepsilon}}$ is the observation error covariance matrix, and the superscript $\mathrm{T}$ stands for the matrix transposition. The NARA algorithm uses the NLS-4DVar method to minimize the cost function. 


\section{NLS-4DVar Method}

The NLS-4DVar method (Tian and Feng, 2015; Tian et al., 2018) rewrites the cost function in Eq. 2 into an incremental format to determine the analysis increment for the a priori state vector:

$$
\begin{aligned}
\chi^{2}\left(\boldsymbol{x}^{\prime}\right)=\frac{1}{2}\left(\boldsymbol{x}^{\prime}\right)^{\mathrm{T}} \mathbf{S}_{a}^{-1}\left(\boldsymbol{x}^{\prime}\right) & +\frac{1}{2}\left[F^{\prime}\left(\boldsymbol{x}^{\prime}\right)-\boldsymbol{y}^{\prime}\right]^{\mathrm{T}} \mathbf{S}_{\varepsilon}^{-1}\left[F^{\prime}\left(\boldsymbol{x}^{\prime}\right)-\boldsymbol{y}^{\prime}\right] \\
F^{\prime}\left(\boldsymbol{x}^{\prime}\right) & =F\left(\boldsymbol{x}_{a}+\boldsymbol{x}^{\prime}\right)-F\left(\boldsymbol{x}_{a}\right) \\
\boldsymbol{y}^{\prime} & =\boldsymbol{y}-F\left(\boldsymbol{x}_{a}\right)
\end{aligned}
$$

where $\boldsymbol{x}^{\prime}=\boldsymbol{x}-\boldsymbol{x}_{a}$ is the perturbation of the prior field $\boldsymbol{x}_{a}, \boldsymbol{y} \in \mathbb{R}^{n_{y}}$, and $n_{y}$ is the dimension of the observation. To avoid the direct inversion of the a priori covariance matrix $\mathbf{S}_{a}$, the NLS-4DVar method expresses the analysis increment $\boldsymbol{x}^{\prime, *}$ as a linear combination of the initial perturbations:

$$
\boldsymbol{x}^{\prime, *}=\mathbf{P}_{x} \boldsymbol{\beta}
$$

where $\mathbf{P}_{\boldsymbol{x}}=\left(\boldsymbol{x}_{1}^{\prime}, \boldsymbol{x}_{2}^{\prime}, \ldots, \boldsymbol{x}_{\mathrm{N}}^{\prime}\right)$ is the ensemble of prepared initial perturbations, $\boldsymbol{x}_{j}^{\prime}=\boldsymbol{x}_{j}-\boldsymbol{x}_{a}(j=1,2, \ldots, N)$ is the $j$ th perturbation, $N$ is the ensemble size, and $\boldsymbol{\beta}=\left(\beta_{1}, \beta_{2}, \ldots, \beta_{N}\right)^{\mathrm{T}}$ is the coefficient vector. A reasonable ensemble of perturbations $\mathbf{P}_{x}$ can provide an appropriate solution space for the analysis increment $\boldsymbol{x}^{\prime, *}$. We further assume that the a priori covariance matrix can be approximated by the ensemble covariance matrix $\mathbf{B}_{e}$, that is, $\mathbf{S}_{a} \approx \mathbf{B}_{e}=\left(\mathbf{P}_{x}\right)\left(\mathbf{P}_{x}\right)^{\mathrm{T}} / N-1$. As the ensemble of perturbations is updated with iterations, the a priori covariance matrix $\mathbf{S}_{a}$ will also be updated. Compared with the general methods that use a fixed $\mathbf{S}_{a}$, this constantly updated $\mathbf{S}_{a}$ tends to be more precise as the iteration progresses. Substituting the above assumptions into Eq. 3 yields

$$
\chi^{2}(\boldsymbol{\beta})=\frac{1}{2}(N-1) \times \boldsymbol{\beta}^{\mathrm{T}} \boldsymbol{\beta}+\frac{1}{2}\left[F^{\prime}\left(\mathbf{P}_{x} \boldsymbol{\beta}\right)-\boldsymbol{y}^{\prime}\right]^{\mathrm{T}} \mathbf{S}_{\varepsilon}^{-1}\left[F^{\prime}\left(\mathbf{P}_{x} \boldsymbol{\beta}\right)-\boldsymbol{y}^{\prime}\right]
$$

Obviously, Eq. 7 can be solved iteratively by computing the cost function and its gradient:

$$
\nabla \chi^{2}(\boldsymbol{\beta})=(N-1) \boldsymbol{\beta}+\left(\mathbf{P}_{x}\right)^{\mathrm{T}}(\mathbf{K})^{\mathrm{T}} \mathbf{S}_{\varepsilon}^{-1}\left[F^{\prime}\left(\mathbf{P}_{x} \boldsymbol{\beta}\right)-\boldsymbol{y}^{\prime}\right]
$$

where $\mathbf{K}=\partial F(\boldsymbol{x}) / \partial \boldsymbol{x}$ is the weighting function matrix (tangent linear model) and $(\mathbf{K})^{\mathrm{T}}$ is the transposition of the weighting function matrix (adjoint model). The programming difficulty and computational complexity of the weighting function matrix and its transposition are huge; combined with the large number of satellite measurements, this greatly increases the computational cost. This is a problem faced by some other algorithms (Connor et al., 2008; Butz et al., 2009; Yoshida et al., 2011; Butz et al., 2012; Cogan et al., 2012).

To circumvent the calculation of the weighting function matrix and its transposition, the NLS-4DVar method converts Eq. 7 into the following nonlinear least squares problem:

$$
\begin{gathered}
\chi^{2}(\boldsymbol{\beta})=\frac{1}{2} Q(\boldsymbol{\beta})^{\mathrm{T}} Q(\boldsymbol{\beta}), \\
Q(\boldsymbol{\beta})=\left\{\begin{array}{c}
\sqrt{N-1} \boldsymbol{\beta} \\
\mathbf{S}_{\varepsilon,+}^{-1 / 2}\left[F^{\prime}\left(\mathbf{P}_{x} \boldsymbol{\beta}\right)-\boldsymbol{y}^{\prime}\right]
\end{array}\right\} .
\end{gathered}
$$

Here $\left(\mathbf{S}_{\varepsilon,+}^{1 / 2}\right)\left(\mathbf{S}_{\varepsilon,+}^{1 / 2}\right)^{\mathrm{T}}=\mathbf{S}_{\varepsilon}$. The Gauss-Newton iteration method (Dennis and Schnabel, 1996) is used to minimize the cost function. After a simple mathematical derivation, the optimal state vector is obtained without calculating the weighting function matrix and its transposition, which is shown in Appendix A. The final formula is given below (Tian et al., 2018):

$$
\begin{gathered}
\delta \boldsymbol{\beta}^{i-1}=\left(\mathbf{P}_{y}^{\#, i-1}\right)^{\mathrm{T}} \mathbf{S}_{\varepsilon}^{-1} \boldsymbol{y}^{, i-1}+\left(\mathbf{P}_{x}^{\#, i-1}\right)^{\mathrm{T}} \boldsymbol{x}^{, i-1, *}, \\
\delta \boldsymbol{x}^{i-1, *}=\mathbf{P}_{x}^{i-1} \delta \boldsymbol{\beta}^{i-1}, \\
\boldsymbol{x}^{i, *}=\boldsymbol{x}^{i-1, *}+\delta \boldsymbol{x}^{i-1, *},
\end{gathered}
$$

where $\boldsymbol{y}^{\prime, i-1}=\boldsymbol{y}-F\left(\boldsymbol{x}^{i-1, *}\right), \boldsymbol{x}^{i-1, *}$ is the optimal analysis of the state vector in the last step, and

$$
\begin{aligned}
\left(\mathbf{P}_{y}^{\#, i-1}\right)^{\mathrm{T}}= & {\left[(N-1) \mathbf{I}+\left(\mathbf{P}_{y}^{i-1}\right)^{\mathrm{T}} \mathbf{S}_{\varepsilon}^{-1}\left(\mathbf{P}_{y}^{i-1}\right)\right]^{-1}\left(\mathbf{P}_{y}^{i-1}\right)^{\mathrm{T}} } \\
\left(\mathbf{P}_{x}^{\#, i-1}\right)^{\mathrm{T}}= & -(N-1)\left[(N-1) \mathbf{I}+\left(\mathbf{P}_{y}^{i-1}\right)^{\mathrm{T}} \mathbf{S}_{\varepsilon}^{-1}\left(\mathbf{P}_{y}^{i-1}\right)\right]^{-1} \\
& \times\left[\left(\mathbf{P}_{x}^{i-1}\right)^{\mathrm{T}}\left(\mathbf{P}_{x}^{i-1}\right)\right]^{-1}\left(\mathbf{P}_{x}^{i-1}\right)^{\mathrm{T}}
\end{aligned}
$$

where

$$
\begin{gathered}
\mathbf{P}_{y}^{i-1}=\left(\boldsymbol{y}_{1}^{\prime, i-1}, \boldsymbol{y}_{2}^{\prime, i-1}, \ldots, \boldsymbol{y}_{N}^{\prime, i-1}\right) \\
\boldsymbol{y}_{j}^{, j-1}=F\left(\boldsymbol{x}^{i-1, *}+\boldsymbol{x}_{j}^{\prime, i-1}\right)-F\left(\boldsymbol{x}^{i-1, *}\right)=F\left(\boldsymbol{x}_{a}+\boldsymbol{x}_{j}^{\prime}\right)-F\left(\boldsymbol{x}^{i-1, *}\right) \\
\mathbf{P}_{x}^{i-1}=\left(\boldsymbol{x}_{1}^{\prime, i-1}, \boldsymbol{x}_{2}^{\prime, i-1}, \ldots, \boldsymbol{x}_{N}^{,, i-1}\right) \\
\boldsymbol{x}_{j}^{\prime, i-1}=\boldsymbol{x}_{j}^{\prime}+\boldsymbol{x}_{a}-\boldsymbol{x}^{i-1, *}
\end{gathered}
$$

According to Tian et al. (2018), the cost function generally reaches the minimum convergence standard after three iterations. Here the optimal state vector contains the $\mathrm{CO}_{2}$ profile component, allowing the calculation of the best estimation of $X_{\mathrm{CO} 2}$.

\section{Initial Ensemble Generation}

As mentioned above, the NLS-4DVar method assumes that the analysis increment can be expressed as the linear combination of the initial perturbations; the quality of the initial ensemble of perturbations is vital to the success of the retrieval. For different components in the state vector, we use different initial ensemble generation methods. The $\mathrm{CO}_{2}$ profile ensemble of perturbations is generated by the random state variable (RSV) method (Zhang, 2019), the ensembles of the other components are generated by normal distributions.

The RSV method first requires a big ensemble of perturbations. The method then performs singular value decomposition and the random orthogonal matrix to obtain the final small ensemble (Evensen, 2009). The big ensemble comes from the model simulated $\mathrm{CO}_{2}$ of GEOS-Chem (v11-01; http://acmg.seas.harvard. edu/geos/). There are seven carbon fluxes used to drive GEOS-Chem: fossil fuel emissions, ocean carbon fluxes, terrestrial ecosystem fluxes, biomass burning emissions, ships emissions, aviation emissions, and chemical oxidation production. The ocean carbon fluxes and terrestrial ecosystem fluxes are optimized by the Tan-Tracker flux inversion system (Tian et al., 2014a; Tian et al., 2014b) through assimilating OCO-2 $X_{\mathrm{CO} 2}$ retrievals. GEOS-Chem simulates the $\mathrm{CO}_{2}$ profile at 47 atmospheric pressure levels, with a horizontal resolution of $2^{\circ}$ latitude $\times 2.5^{\circ}$ longitude. The 47 pressure levels are defined using the hybrid sigma-pressure grid, and the top atmospheric pressure level is about $0.038 \mathrm{hPa}$ 
(http://wiki.seas.harvard.edu/geos-chem/index.php/GEOS-Chem_ vertical_grids\#Hybrid_grid_definition, last access: June 3, 2021). In order to avoid the size of big ensemble being too large, the $\mathrm{CO}_{2}$ profile is taken every 4 grid points along the longitude and the daily average $\mathrm{CO}_{2}$ profile is computed. The profile is then interpolated to the 20 pressure levels, where the $\mathrm{CO}_{2}$ profile in the NARA algorithm is located. According to the month and latitude of the satellite measurement, the model data of the two latitude bands above and below the measurement latitude during an entire month are selected as the big ensemble. For example, consider the measurement at 36. $641^{\circ} \mathrm{N}$ and $97.441^{\circ} \mathrm{W}$ on January 30, 2016. The simulation results of GEOS-Chem at $36.0^{\circ} \mathrm{N}$ and $38.0^{\circ} \mathrm{N}$ in January 2016 show a total of $36 \times 2 \times 31=2232 \mathrm{CO}_{2}$ profiles, which constitute the big ensemble after subtraction of the a priori $\mathrm{CO}_{2}$ profile, denoted by $\mathbf{C}_{e}$. Singular value decomposition of $\mathbf{C}_{e}$ yields

$$
\mathbf{C}_{e}=\mathbf{U} \sum \mathbf{V}
$$

where $\mathbf{U} \in \mathbb{R}^{n_{x} \times n_{x}}, \sum \in \mathbb{R}^{n_{x} \times \alpha N}$, and $\mathbf{V} \in \mathbb{R}^{\alpha N \times \alpha N}$.

$$
\mathbf{C}_{s}=\mathbf{U} \sqrt{\frac{\gamma}{\alpha}} \sum(:, 1: \gamma N) \boldsymbol{\Theta}^{\mathrm{T}} .
$$

Here $\mathbf{C}_{s}$ is the initial ensemble, $1 \leq \gamma \leq \alpha$ and $\Theta \in \mathbb{R}^{N \times \gamma N}$ (Evensen, 2009). $\boldsymbol{\Theta}$ is a random matrix and has orthonormal rows, which can be constructed by extracting the first $N$ rows of the random orthogonal matrix $\Theta \in \mathbb{R}^{\gamma N \times \gamma N}$ (Evensen, 2009). Adding the a priori $\mathrm{CO}_{2}$ profile to the initial ensemble, we obtain the initial $\mathrm{CO}_{2}$ profiles.

The initial ensembles of the other parameters in the state vector are the random perturbations of normal distributions; that is, the mean of the normal distribution takes the prior value. The standard deviations (Table 1) were obtained by sensitivity experiments and analysing OCO-2 data. The initial ensemble of the state vector is constructed by combining the $\mathrm{CO}_{2}$ profile ensemble and the remaining parameter ensembles together. Add the $a$ priori state vector to the ensemble and input it into the forward model to obtain the simulated spectra. After preparing the above data, we can determine the optimal estimate of $X_{\mathrm{CO} 2}$ using the NLS-4DVar method introduced in Sect. 2.2.1.

\section{OBSERVING SYSTEM SIMULATION EXPERIMENTS FOR EVALUATING THE (NLS-4DVAR)-BASED $\mathrm{CO}_{2}$ RETRIEVAL ALGORITHM}

In this section, we evaluated the NARA algorithm comprehensively by performing observing system simulation experiments (OSSEs) at four different sites around the world. Besides, we conducted a set of experiments at one site, discussing the effects of aerosol amounts on $X_{\mathrm{CO} 2}$ retrievals.

\section{Experimental Setup}

A total of four sites around the world were selected for retrievals. Three were near Total Carbon Column Observing Network (TCCON) (Wunch et al., 2011) stations, specifically the Lamont (LA), Bremen (BR), and Wollongong (WO) stations, and the remaining one was on the North Pacific (OC).
Information on these four sites is listed in Table 2, and their specific locations are shown in Figure 2. The impacts of surface properties, latitudes, seasons, and land-sea distribution on retrievals were carefully considered when selecting the retrieval sites to ensure the comprehensiveness of the experiments. Especially, previous studies have indicated that scenes without aerosol contamination could yield better results, and $X_{\mathrm{CO} 2}$ retrieval biases appeared to be correlated with scattering by aerosols (Wunch et al., 2017; O'Dell et al., 2018). Thus, we performed a set of OSSEs at the Lamont station to evaluate retrieval results under different aerosol amounts.

We used OCO-2 version eight retrospective (i.e., 8r) data in the OSSEs, including Level 1B data OCO2_L1B_Calibration 8r, meteorological data OCO2_L2_Met 8r, pre-screening data OCO2_L2_ABand 8r, and OCO2_IMAPDOAS 8r, as well as diagnostic data OCO2_L2_Diagnostic 8r (https://disc.gsfc.nasa. gov/datasets?keywords $=$ oco $2 \&$ sort $=$ processLevel\&page $=1$ ). The pre-screening procedure uses $\mathrm{ABO}_{2}$ and IMAP-DOAS preprocessors to remove scenes contaminated by clouds or aerosols (Taylor et al., 2016). The diagnostic data provide prior and retrieved state vectors and prior $X_{\mathrm{CO} 2}$ in the OSSEs. We used target-mode data for the three retrieval sites over land and glint-mode data for the retrieval site over the ocean. We generated the initial ensemble following the method introduced in Sect. 2.2.2, and we chose 50 for the size of the ensemble after sensitivity experiments.

In OSSEs, the a priori state vector adopts the a priori value calculated by OCO-2 according to the input data, and the constructed true state vector adopts the OCO-2 retrieval result of the observation point or a nearby point. The constructed true state vector is input into the forward model to obtain the simulated spectra. The observation error of OCO- 2 is then added to the simulated spectra to obtain the observation spectra. The a priori $\mathrm{CO}_{2}$ profile and constructed true $\mathrm{CO}_{2}$ profile are shown in Figure 6. The spectra simulated by the $a$ priori state vector and constructed observation spectra are shown in Figure 3. For the aerosol specific evaluation, we conducted a set of OSSEs at the Lamont station on January 3, 2016 under three different tropospheric aerosol amounts. The two tropospheric aerosol types were sulfate and organic carbon. As the values of $\ln (\mathrm{AOD})$ at $755 \mathrm{~nm}$ are used in the state vector, we chose three sets of $\ln (\mathrm{AOD})$ for these two aerosols. For $\ln (\mathrm{AOD})$ of sulfate and organic carbon, they were -4.47 and $-5.97,-5.47$ and -6.97 , -10.47 and -11.97 , respectively in the three sets.

\section{Experimental Results}

The retrieval quality was evaluated in terms of the $X_{\mathrm{CO} 2}$ and $\mathrm{CO}_{2}$ profiles. $X_{\mathrm{CO} 2}$ is the product currently provided by satellite retrievals, and accurate $\mathrm{CO}_{2}$ profiles are the goals of retrieval algorithms.

\section{$X_{\mathrm{CO} 2}$ Results}

The differences between the a priori $X_{\mathrm{CO} 2}$ and the true $X_{\mathrm{CO} 2}$ were relatively large; specifically, LA, BR, WO, and OC showed differences of $1.88,1.70,-3.15$, and $2.27 \mathrm{ppm}$, respectively. Figure 4 shows the $X_{\mathrm{CO} 2}$ obtained by the NARA algorithm after one, two, and three iterations and comparisons with the $a$ priori $X_{\mathrm{CO} 2}$ and the true $X_{\mathrm{CO} 2}$ at the four retrieval sites. The 
TABLE 2 | Information on the four retrieval sites in the OSSEs, including the observation date, sounding ID, location (listed in degrees latitude and degrees longitude), and surface properties. (LA: Lamont; BR: Bremen; WO: Wollongong; OC: the ocean site).

\begin{tabular}{|c|c|c|c|c|}
\hline Site & Observation date & Sounding ID & Location (lat, long) & Properties \\
\hline LA & $2016-1-3$ & 2016010319450071 & $36.641,-97.441$ & Land; northern hemisphere \\
\hline $\mathrm{BR}$ & $2016-3-17$ & 2016031712125573 & $53.088,8.888$ & Land; northern hemisphere \\
\hline WO & $2016-2-10$ & 2016021003570833 & $-34.410,150.875$ & Land; southern hemisphere \\
\hline OC & $2016-7-1$ & 2016070101072675 & $19.676,-177.231$ & Ocean; northern hemisphere \\
\hline
\end{tabular}

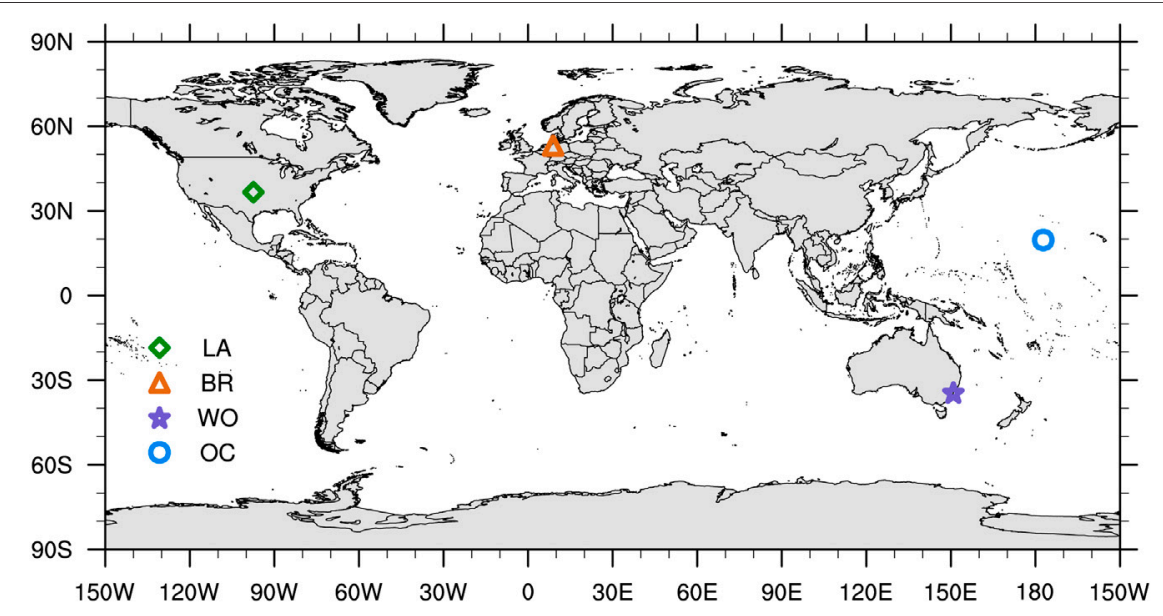

FIGURE 2 | Map of the four retrieval sites in OSSEs. (LA, Lamont; BR, Bremen; WO, Wollongong; OC, the ocean site).

retrieved $X_{\mathrm{CO} 2}$ gradually approached the true value as the iterations of the NARA algorithm progressed, ultimately reaching the optimal value at the third iteration. The differences between the NARA retrieved $X_{\mathrm{CO} 2}$ and the true $X_{\mathrm{CO} 2}$ after three iterations were $0.33,0.11,0.11$, and $-1.13 \mathrm{ppm}$ at LA, BR, WO, and OC, respectively, which was a big improvement from the prior $X_{\mathrm{CO} 2}$ and showed that our algorithm was effective.

The retrievals at LA and WO were similar. At these two sites, the retrieval of the first iteration was very effective, with subsequent iterations approaching the true value. After three iterations, the NARA retrieved $X_{\mathrm{CO} 2}$ was quite close to the true $X_{\mathrm{CO} 2}$. The results for $\mathrm{BR}$ and $\mathrm{OC}$ were similar. The retrieval of the first iteration was significantly changed compared with the prior value, which showed that observation information had a huge impact on retrieval. In subsequent iterations at $\mathrm{BR}$ and $\mathrm{OC}$, under the mutual constraints of the prior information and observations, the retrieved $X_{\mathrm{CO} 2}$ gradually approached the true value and reached the optimal $X_{\mathrm{CO} 2}$ at the third iteration. The NARA retrieved $X_{\mathrm{CO} 2}$ of the three retrieval sites over land were closer to the true $X_{\mathrm{CO} 2}$ than the NARA retrieved $X_{\mathrm{CO} 2}$ at the ocean site OC, which was attributable to the different observation modes and surface properties over land and ocean and/or the varying accuracies of the prior values.

The NARA retrieved $X_{\mathrm{CO} 2}$ depended on atmospheric AODs (Figure 5A). The prior and true $X_{\mathrm{CO} 2}$ at the observation site were $402.49 \mathrm{ppm}$ and $400.61 \mathrm{ppm}$. The NARA retrieved $X_{\mathrm{CO} 2}$ for scenario 1 (S1), scenario 2 (S2), and scenario 3 (S3) were 400.94, 401.13, and $401.24 \mathrm{ppm}$, respectively. S1 had the highest AOD while S3 had the lowest AOD. It's clear that as the AOD decreased, the bias of retrieved $X_{\mathrm{CO} 2}$ increased, which indicated that more accurate $X_{\mathrm{CO} 2}$ can be retrieved under atmospheric conditions with less aerosols.

\section{$\mathrm{CO}_{2}$ Profile Results}

Figure 6 shows the $\mathrm{CO}_{2}$ profiles obtained by the NARA algorithm after one, two, and three iterations and comparisons with the $a$ priori $\mathrm{CO}_{2}$ profile and the true $\mathrm{CO}_{2}$ profile at the four retrieval sites. The $\mathrm{CO}_{2}$ profiles differed between the Northern and Southern hemispheres. The vertical gradient of the $\mathrm{CO}_{2}$ profile in the Northern Hemisphere was larger than in the Southern Hemisphere, which is depicted in Figure 6.

First look at the retrieval results for the two Northern Hemisphere sites LA and BR. The vertical gradient of the $a$ priori $\mathrm{CO}_{2}$ profile was relatively small. The true $\mathrm{CO}_{2}$ profile above the troposphere was in good agreement with the a priori $\mathrm{CO}_{2}$ profile; however, the vertical gradient in the troposphere was greater than that of the a priori profile. As the iterations progressed, the NARA retrieved $\mathrm{CO}_{2}$ profile gradually approached the true value. After three iterations, the NARA retrieved $\mathrm{CO}_{2}$ profile was very close to the true profile, in particular in the lower troposphere. This is particularly important given that the carbon sources and sinks of interest are all located in the lower troposphere. A close look at the retrieval results for the two Southern Hemisphere sites WO and OC shows that the vertical gradient of the a priori $\mathrm{CO}_{2}$ profile in the troposphere was quite small. The NARA retrieved $\mathrm{CO}_{2}$ profiles roughly grasped the characteristics of the true profiles; 

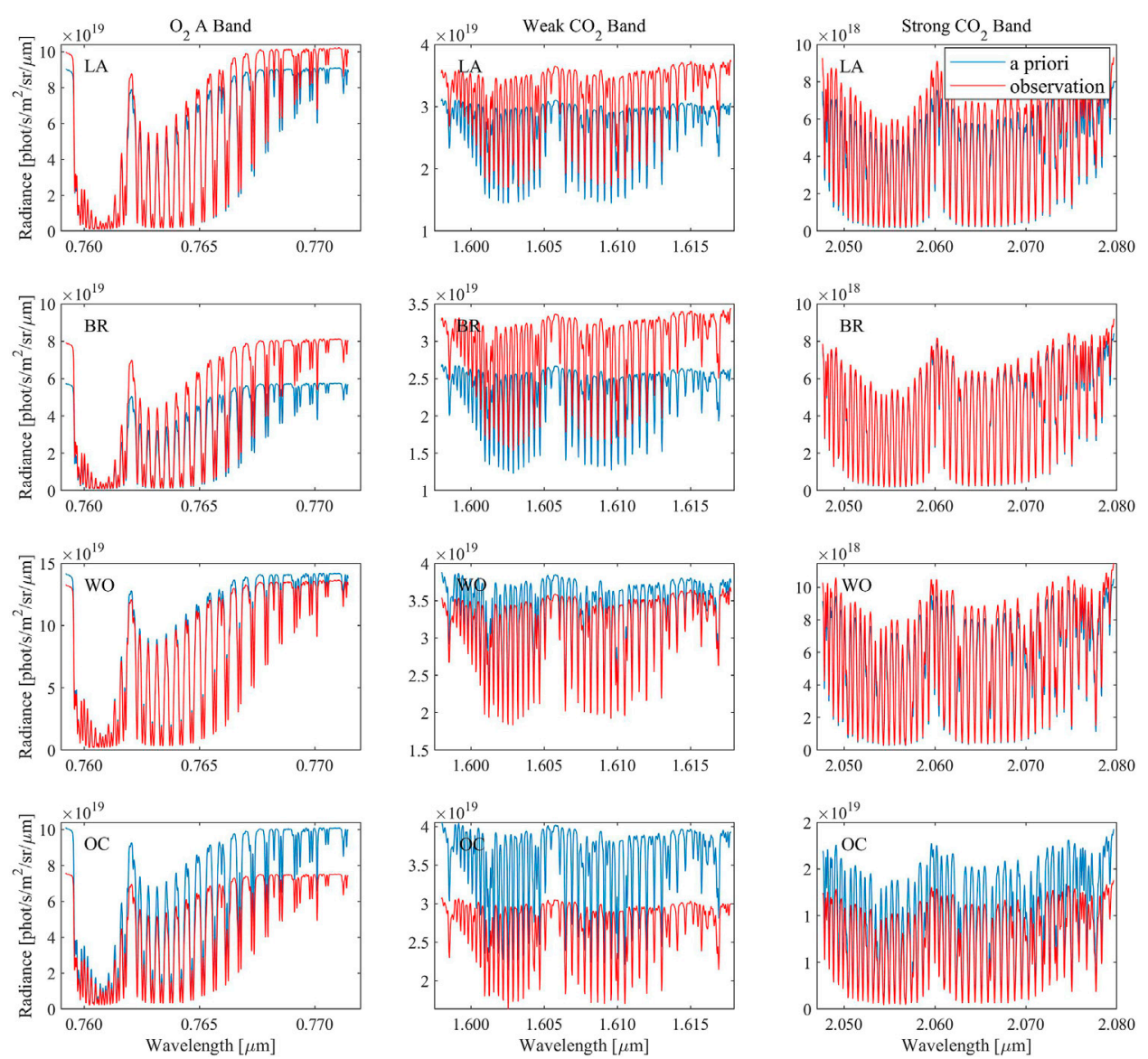

FIGURE 3 | Spectra simulated by the a priori state vector and constructed observation spectra in three bands. The first column is the $\mathrm{O}_{2} \mathrm{~A}$ band, the second column is the weak $\mathrm{CO}_{2}$ band, and the third column is the strong $\mathrm{CO}_{2}$ band. The first to fourth rows are the spectra at $\mathrm{LA}, \mathrm{BR}$, WO, and OC, respectively. The name of the observation point is in the upper left corner of each subplot.

however, they were unable to well simulate the relatively large vertical gradient of the true profile in the lower troposphere, which were not as good as the results for the Northern Hemisphere. Because the vertical gradient of the a priori $\mathrm{CO}_{2}$ profile in the Southern Hemisphere was small, the vertical gradient of the $\mathrm{CO}_{2}$ profile ensemble decomposed on the basis of the prior value was also small. The analysis increment was a linear combination of the ensemble members, thus it could not retrieve well a large vertical gradient as the true profile indicated. This problem may be solved by providing a better prior $\mathrm{CO}_{2}$ profile. The retrieved $\mathrm{CO}_{2}$ profile can also be influenced by aerosol contents (Figure 5B). The patterns of the $\mathrm{CO}_{2}$ profile under different AODs were similar, but the specific $\mathrm{CO}_{2}$ concentrations at each level were various, which contributed to the discrepancy of the column-averaged value. The above analyses demonstrate that the NARA retrieved $\mathrm{CO}_{2}$ profiles in the Northern Hemisphere were relatively accurate, in particular in the lower troposphere. The retrieval results for the Southern Hemisphere roughly grasped the characteristics of the true profiles but still needed more improvement. The effects of aerosol scattering should also be considered during the retrievals.

\section{REAL-DATA RETRIEVALS AND COMPARISONS WITH TOTAL CARBON COLUMN OBSERVING NETWORK DATA}

In this section, we evaluated the $X_{\mathrm{CO} 2}$ retrieved by the NARA algorithm using OCO-2 version $8 \mathrm{r}$ target-mode observations at two target locations and compared the NARA retrieved $X_{\mathrm{CO} 2}$ with coincident TCCON data. TCCON is a global network of ground-based instruments that can retrieve accurate and precise $X_{\mathrm{CO} 2}$, which provides an essential validation resource for spacebased measurements (Wunch et al., 2011). In addition, we performed real retrievals using the normal 4DVar method, which requires the calculation of the pressure weighting function and its transposition, and compared the retrievals with NARA retrieved ones.

\section{Experimental Setup}

Target mode is designed to evaluate biases in the OCO-2 $X_{\mathrm{CO} 2}$ product, whose strength is that thousands of spectra can be obtained in a short period of time over a small region (about $0.2^{\circ}$ latitude $\times 0.2^{\circ}$ longitude for the densest measurements) 

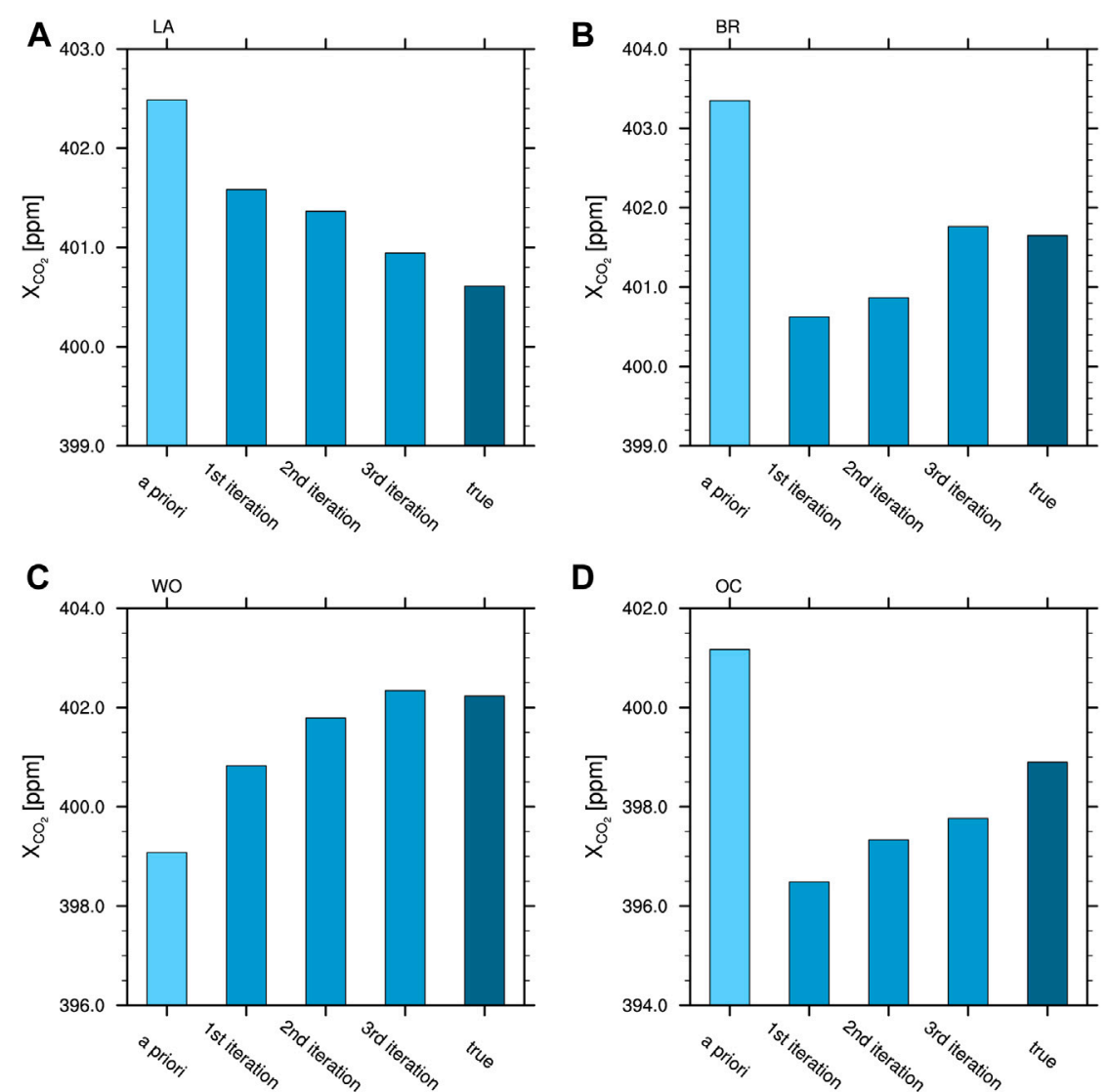

FIGURE 4 | NARA retrieved $X_{\mathrm{CO} 2}$ after one, two, and three iterations and comparisons with the a priori $X_{\mathrm{CO} 2}$ and the true $X_{\mathrm{CO} 2}$ at (A) LA, (B) BR, (C) WO, and (D) OC.
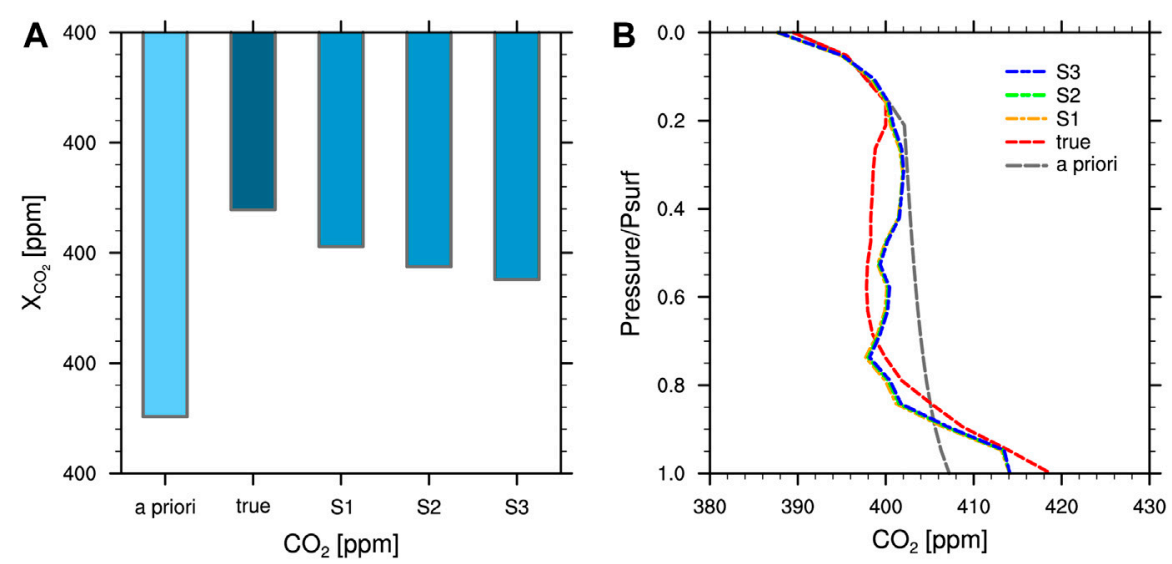

FIGURE 5 | The prior and true values as well as NARA retrievals with different atmospheric AODs. (A) depicts the $\mathrm{CO}_{2}$ profiles, and (B) depicts the $X_{\mathrm{CO}}$. S1, $\mathrm{S} 2$, and S3 indicates scenario 1, scenario 2, and scenario 3, respectively. 

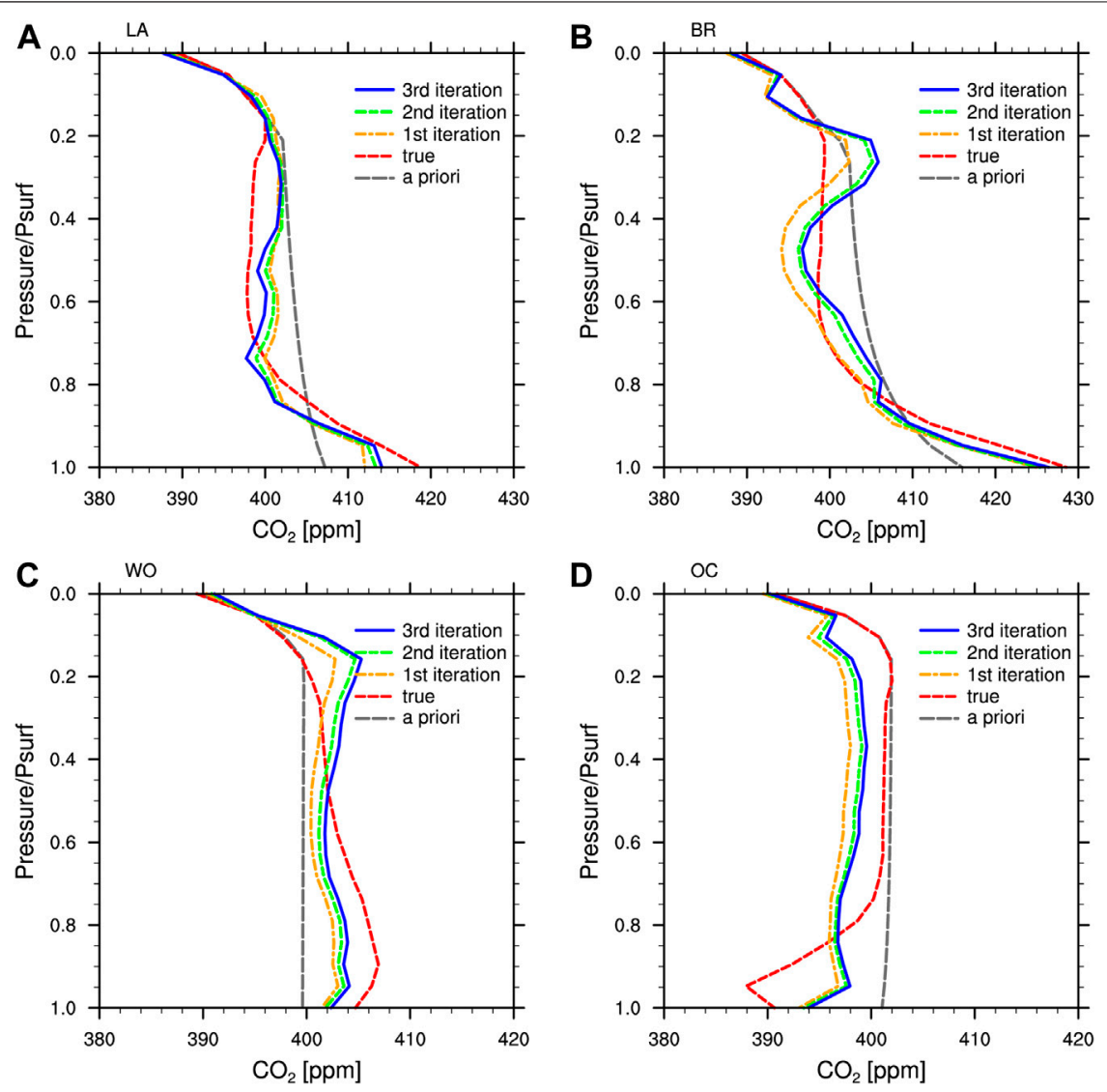

FIGURE 6 | NARA retrieved $\mathrm{CO}_{2}$ profiles after one, two, and three iterations and comparisons with a priori and true $\mathrm{CO}_{2}$ profiles at (A) LA, (B) BR, (C) WO, and (D) OC.

(Wunch et al., 2017). The target locations are mostly selected to be coincident with ground-based stations, typically at TCCON sites (Wunch et al., 2011). Given the differences between the Northern and Southern hemispheres, the two target locations selected for validation were Lamont, Oklahoma, in the central United States and Darwin, Australia, on the northern coast. The Lamont location has relatively uniform surface properties and is reasonably far from anthropogenic $\mathrm{CO}_{2}$ sources, and the ground cover changes with the seasons (Wunch et al., 2017); in contrast, target-mode measurements at the Darwin location contain observations over both land and ocean. Information on these two target locations is shown in Table 3. OCO-2 measurements over about 1 year were selected for validation at each of the two locations. The observation dates are listed in Table 4.

Restricted by our computational resources, we randomly selected 10 observation points from OCO-2 pre-screened measurements for retrievals each day at the Lamont location; for the Darwin location, we randomly selected 10 observation points over land and 10 observation points over the ocean each day. For the $4 \mathrm{DV}$ ar retrievals, we performed experiments at the Lamont station on November 24,2014 . We retrieved $X_{\mathrm{CO} 2}$ at the same 10 observation points and used the same prior values as the
NARA algorithm. We assumed that TCCON data were coincident with OCO-2 target-mode measurements when they were recorded within \pm 30 min of the target-mode maneuver. If there were fewer than five TCCON measurements within that time frame, the period was extended to $\pm 120 \mathrm{~min}$. Then we compared the median of the NARA retrieved $X_{\mathrm{CO} 2}$ of the 10 selected observation points with the median of coincident TCCON measurements. In the real retrievals, the size of the initial ensemble was 50, and the number of iterations was three. Then we corrected the NARA retrieved $X_{\mathrm{CO} 2}$ for bias using the OCO-2 bias correction method (O’Dell et al., 2018).

\section{Experimental Results}

Figure 7 shows the median of the NARA retrieved $X_{\mathrm{CO} 2}$ and comparisons with the median of the OCO-2 retrieved $X_{\mathrm{CO} 2}$ using the ACOS algorithm for the same observation points and the median of the coincident TCCON measurements at Lamont and Darwin locations. Retrievals over the land and ocean at the Darwin location were evaluated separately because land and ocean surface reflections were modelled differently as purely Lambertian over land and Cox-Munk with a Lambertian component over water (O'Dell et al., 2018). The $X_{\mathrm{CO} 2}$ 
TABLE 3 | Information on the two validated target locations for real retrievals. The target location is listed in degrees latitude, degrees longitude, and altitude above sea level in $\mathrm{km}$.

\begin{tabular}{|c|c|c|c|}
\hline Target & $\begin{array}{l}\text { Target location } \\
\text { (lat, long, alt) }\end{array}$ & Target active dates & Data References \\
\hline Lamont, Oklahoma & $36.604,-97.486,0.3179$ & July 2014-present & Wennberg et al. (2016) \\
\hline Darwin, Australia & $-12.375,130.917,0.0049$ & July 2014-present & Griffith et al. (2014) \\
\hline
\end{tabular}

TABLE 4 | Dates of the target-mode observations selected for real retrievals at the two validated target locations.

Target

Date

Lamont, Oklahoma

Darwin, Australia

2014-10-3, 2014-10-30, 2014-11-24, 2015-2-10, 2015-2-19, 2015-3-3, 2015-6-20, 2015-9-4, 2015-10-10, 2015-11-2, 2015-12-2 2014-9-8, 2014-9-15, 2014-9-22, 2015-3-19, 2015-5-15, 2015-6-5, 2015-8-1, 2015-8-10, 2015-9-11

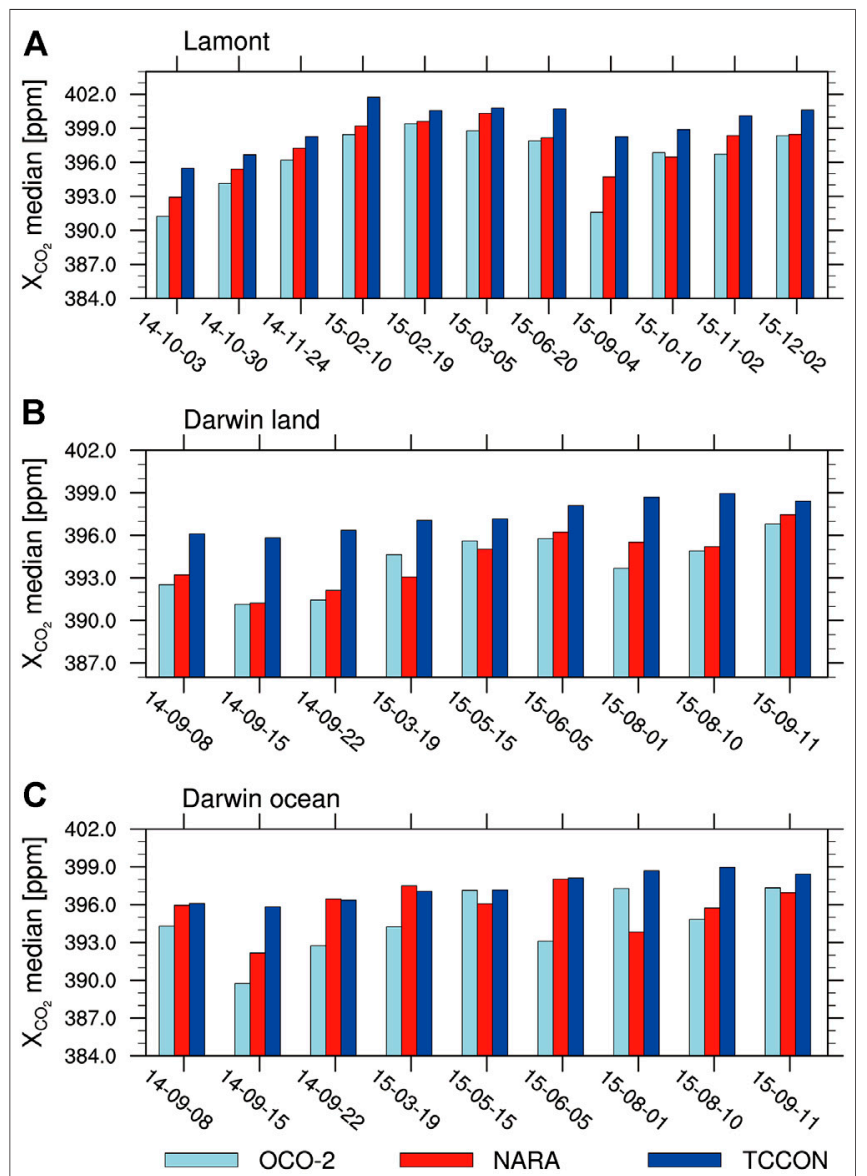

FIGURE 7 | The median of the NARA retrieved $X_{\mathrm{CO} 2}$ and comparisons with median of the OCO-2 retrieved $X_{\mathrm{CO} 2}$ for the same observation points and the median of the coincident TCCON data at $\mathbf{( A )}$ the Lamont location, $(\mathbf{B})$ the Darwin location over land, and $(\mathbf{C})$ the Darwin location over the ocean.

retrieved by the NARA algorithm and OCO-2 were generally smaller than TCCON data, in particular over land. It is common for OCO-2 that a retrieved $X_{\mathrm{CO} 2}$ will be smaller than TCCON data. The NARA algorithm uses similar state vector setting and aerosol characterization as the ACOS algorithm; thus, some
TABLE 5 | Bias (b) and sounding precision ( $\sigma$ ) of NARA and OCO-2 real retrievals at the two validated target locations. The units for $b$ and $\sigma$ are ppm.

\begin{tabular}{lccccc}
\hline \multirow{2}{*}{ Target } & \multicolumn{2}{c}{ Bias (b) } & & \multicolumn{2}{c}{ Sounding precision $(\sigma)$} \\
\cline { 2 - 3 } & NARA & OCO-2 & & NARA & OCO-2 \\
\hline Lamont & -1.93 & -2.95 & & 0.91 & 1.49 \\
Darwin & -2.60 & -3.10 & & 1.30 & 1.31
\end{tabular}

features of NARA retrievals are similar to OCO-2 results. This problem may be mitigated by fitting an intensity offset for all three bands and improving aerosol treatments (Wu et al., 2018).

To better evaluate the retrieval quality, we defined the bias $(b)$ as the mean difference between the retrieved $X_{\mathrm{CO} 2}$ from satellite measurements and coincident TCCON data and the sounding precision $(\sigma)$ as the standard deviation of the difference (Wu et al., 2018). The bias and sounding precision obtained by NARA retrievals and OCO-2 retrievals at the Lamont and Darwin locations are shown in Table 5. As shown in Figure 7 and Table 5, medians of the NARA retrieved $X_{\mathrm{CO} 2}$ were generally closer to the TCCON measurements than the OCO-2 retrievals, which demonstrates that the NARA algorithm was effective and the retrievals from NARA were comparable to those from OCO2. For the NARA algorithm, the retrieval results (i.e., bias and sounding precision) differed at the Lamont and Darwin locations, which indicated the existence of location-dependent biases. The location dependence of the target-mode retrievals further showed that spurious variability in the NARA retrieved $X_{\mathrm{CO} 2}$ can be caused by variability in surface properties, such as altitude, albedo, and surface roughness. The NARA retrievals also differed over the land and ocean at the Darwin location; this was attributed to the different surface properties and modelling of the surface reflections.

Define the daily standard deviation $\left(\sigma_{d}\right)$ as the standard deviation of retrieved $X_{\mathrm{CO} 2}$ from 10 selected satellite observation points within a day or the standard deviation of coincident TCCON measurements within a day. Because $X_{\mathrm{CO} 2}$ can be assumed to be constant spatially and temporally during a target maneuver, the daily standard deviation is considered an artifact and can be used to discern biases caused by the 

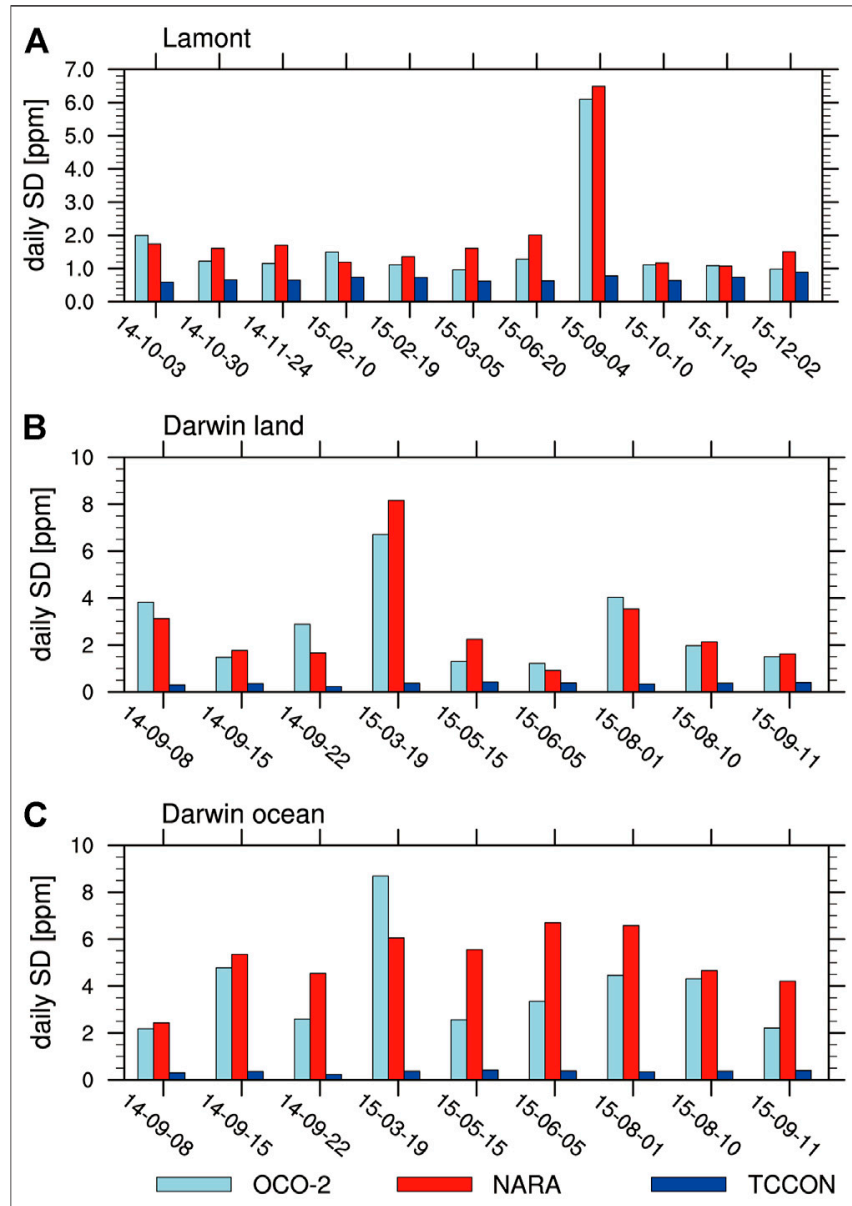

FIGURE 8|Daily standard deviation $(\sigma d)$ of the NARA retrieved $X_{\mathrm{CO} 2}$ and comparisons with od of the OCO-2 retrieved $X_{\mathrm{CO} 2}$ for the same observation points and $\sigma \mathrm{d}$ of the coincident TCCON data at (A) the Lamont location, (B) the Darwin location over land, and (C) the Darwin location over the ocean.

algorithm's processing of parameters. Figure 8 shows the $\sigma_{d}$ of the NARA retrieved $X_{\mathrm{CO} 2}$ and comparisons with $\sigma_{d}$ of the OCO-2 retrieved $X_{\mathrm{CO} 2}$ of the same observation points and $\sigma_{d}$ of the coincident TCCON measurements at the Lamont and Darwin locations. Whether over land or ocean, $\sigma_{d}$ of the two satellite retrievals were larger than that of coincident TCCON measurements. Sometimes $\sigma_{d}$ of satellite retrievals can be particularly large, such as $\sigma_{d}$ on September 4, 2015, at the Lamont location or $\sigma_{d}$ on March 19, 2015, at the Darwin location, which greatly exceeded ground-based values. Although retrievals of 10 randomly selected satellite observation points cannot fully represent the target-mode retrieval, the outcome indicated to a certain extent that ground-based measurements were more robust than satellite retrievals. Comparing the two satellite retrieval results, we found that $\sigma_{d}$ of NARA retrievals were generally larger than those of OCO-2, in particular for measurements at the Darwin location over the ocean. The robustness of the NARA algorithm needs to be improved further, in particular over the ocean, which may be achieved by optimizing the ensemble generation method or imposing more constraints on the parameters of the state vector in the process of minimizing the cost function.

For the further contrast between different optimization methods, the medians and standard deviations of retrievals from 4DVar, NARA, OCO-2, and TCCON at the Lamont station on November 24, 2014 were compared. Without bias correction, the medians of $X_{\mathrm{CO} 2}$ from 4DVar, NARA, OCO-2, and TCCON were 403.28, 397.25, 396.19, and $398.26 \mathrm{ppm}$, respectively. The corresponding standard deviations were 8.85 , $1.70,1.15$, and $0.65 \mathrm{ppm}$, respectively. The $4 \mathrm{DV}$ ar retrieved $X_{\mathrm{CO} 2}$ was much higher than TCCON estimate, and the standard deviation was also bigger than other methods. The NARA median $X_{\mathrm{CO} 2}$ was closest to the TCCON median, and OCO-2 retrievals had the smallest standard deviation. We additionally compared the computational time consumed by each method. The retrieval time of one iteration (excluding forward simulation) from the NARA algorithm was about $0.2-0.3 \mathrm{~s}$. The retrieval time of one iteration for the 4DVar method varied under different circumstances, but most exceeded $1 \mathrm{~s}$. The retrieval time of OCO-2 was close to the 4 DVar method.

Figure 9 shows the variation over time in NARA retrieved $X_{\mathrm{CO} 2}$ and coincident TCCON measurements at the Lamont and Darwin locations. As can be seen from the results for the Lamont location, the NARA retrievals captured well the seasonal variation in $X_{\mathrm{CO} 2}$. In addition, the retrieval results improved greatly after bias correction. After bias correction, the bias $(b)$ was $-0.15 \mathrm{ppm}$, and the sounding precision $(\sigma)$ was $0.76 \mathrm{ppm}$. The seasonal variation in $X_{\mathrm{CO} 2}$ was much smaller in the Southern Hemisphere than in the Northern Hemisphere, and the observation data distribution for the Darwin location was inhomogeneous; therefore, the retrievals at the Darwin location did not show obvious seasonal variation, but $X_{\mathrm{CO} 2}$ increased steadily over time. The bias correction was very effective for observations over land at the Darwin location; however, it was not quite ideal for ocean observations. After the bias correction, the bias $(b)$ was $-0.17 \mathrm{ppm}$, and the sounding precision $(\sigma)$ was $1.26 \mathrm{ppm}$. In this case, we used the bias correction method from OCO-2. Future work will focus on formulating a dedicated bias correction method for the NARA algorithm.

Figure 10 shows the relationship between the median of NARA target-mode retrievals and the median of coincident TCCON data. The best fit straight lines were computed in a least squares sense. Figure 10A shows the relationship prior to bias correction and had a correlation coefficient of $R^{2}=0.89$. Figure 10B shows the retrieval results after bias correction and had a correlation coefficient of $R^{2}=0.90$. Both correlation coefficients passed the significance test at the $5 \%$ level. This demonstrates that the retrieval results were credible and that bias correction was effective, although some residual biases required further investigation.

\section{SUMMARY AND DISCUSSION}

In this study, we developed a novel $\mathrm{CO}_{2}$ retrieval algorithm, NARA, which used the NLS-4DVar method as the optimization method, and adopted the LIDORT radiative transfer model and 

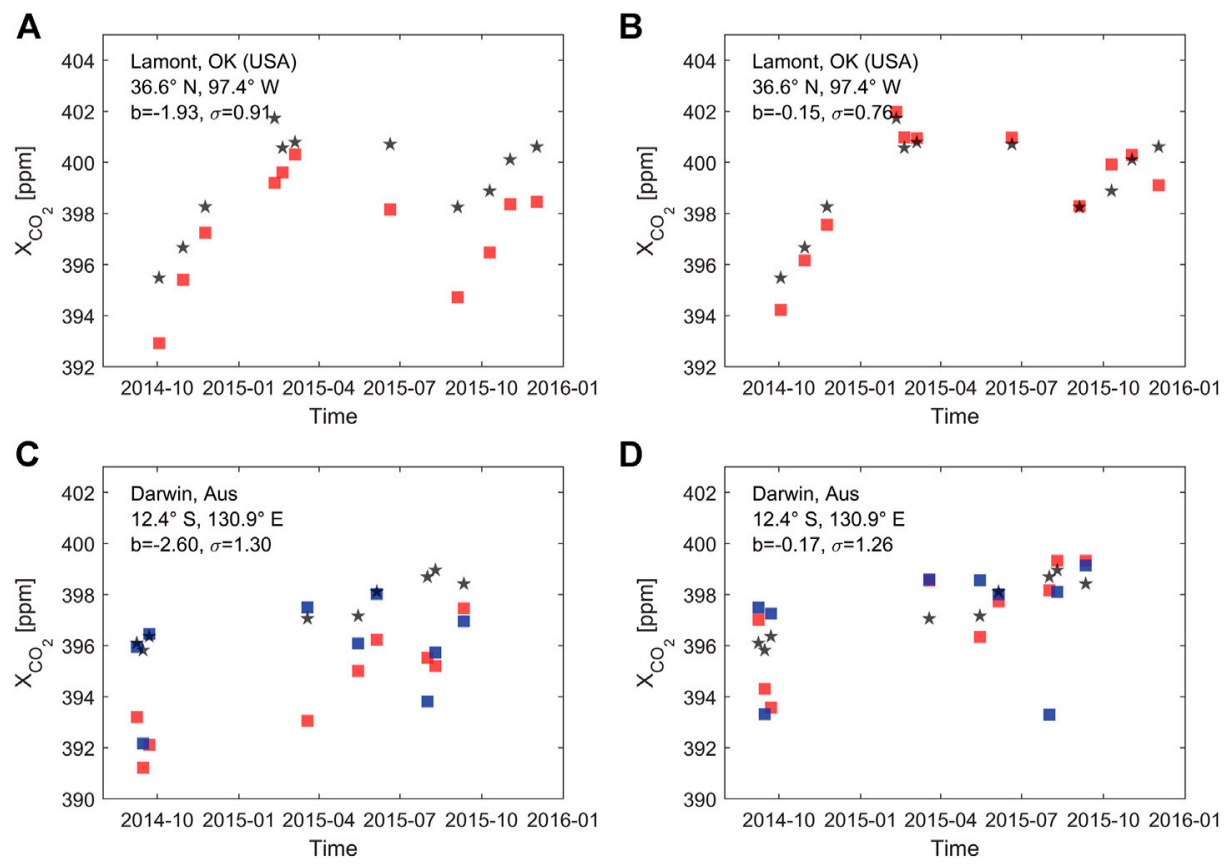

FIGURE 9 | Variation over time in NARA retrieved $X_{\mathrm{CO} 2}$ over land (red squares) and ocean (blue squares) and coincident TCCON measurements (black stars) at the Lamont and Darwin locations. The NARA retrievals in (A) and (C) are before bias correction, and those in (B) and (D) are bias-corrected. In each subplot, the site location in latitude and longitude, bias (B) and sounding precision $(\sigma)$ are presented. The units for $b$ and $\sigma$ are ppm.
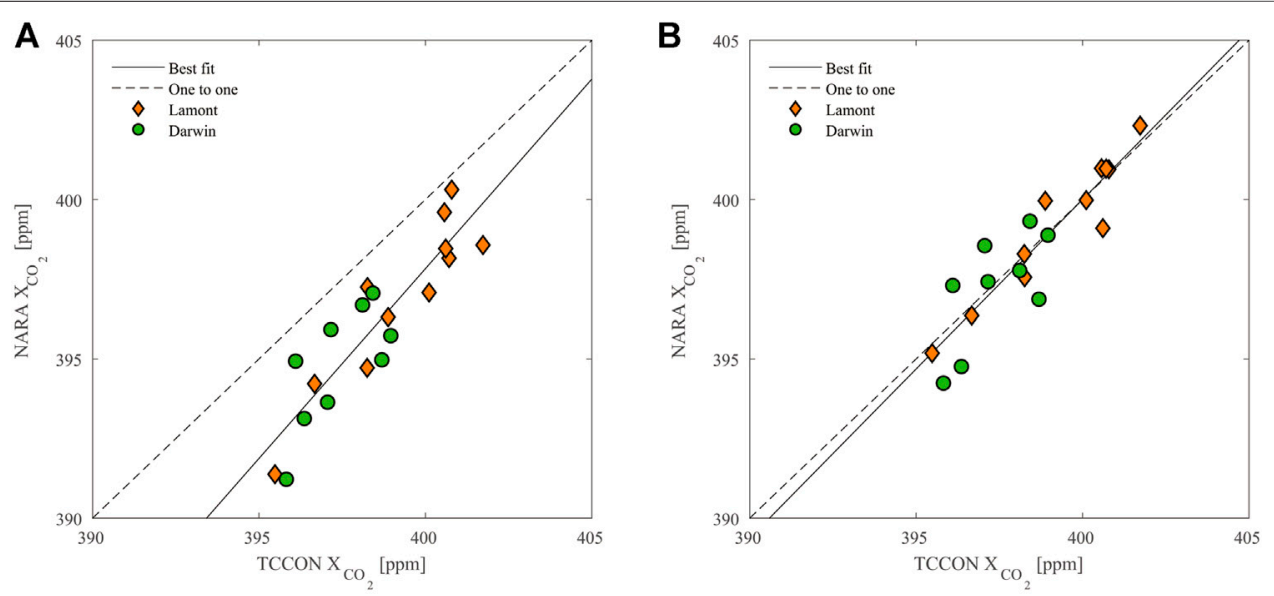

FIGURE 10 | Relationships between the median of NARA target-mode retrievals and the median of coincident TCCON data. (A) Data before bias correction. (B) Data after bias correction. A one-to-one line is indicated by the dashed line, and the best fit line is indicated by the solid line.

necessary parameters provided by the ACOS algorithm in the forward model. The advantages of the NARA algorithm are its simplicity and efficiency given the NLS-4DVar method as its basis, as there is no need to calculate the weighting function matrix and its transposition during the retrieval process. This greatly reduces computational complexity while maintaining retrieval accuracy, which is extremely important for satellite retrievals whose data volume is quite huge.
OSSEs and real-data retrievals were carefully designed to evaluate the NARA algorithm. The OSSEs showed that the NARA retrievals of both $X_{\mathrm{CO} 2}$ and the $\mathrm{CO}_{2}$ profile were greatly improved compared to prior values and were close to the true values. In particular, the retrieved $\mathrm{CO}_{2}$ profiles of the two sites in the Northern Hemisphere over land captured well the real situation in the lower troposphere, where $\mathrm{CO}_{2}$ sources and sinks are located. The effect of aerosol concentrations on $X_{\mathrm{CO} 2}$ retrieval 
was also discussed. We performed a set of three OSSEs with different AODs, and the results indicated that the retrieved $X_{\mathrm{CO} 2}$ was more accurate with lower aerosol concentrations. Then we performed real-data retrievals using OCO-2 target-mode observations and compared the NARA retrieved $X_{\mathrm{CO} 2}$ with coincident TCCON measurements at the Lamont and Darwin locations. Before bias correction, the mean difference between the NARA retrieved $X_{\mathrm{CO} 2}$ and coincident TCCON measurements was $-1.93 \mathrm{ppm}$ (SD: $0.91 \mathrm{ppm}$ ) at the Lamont location; the mean difference was $-2.60 \mathrm{ppm}$ (SD: $1.30 \mathrm{ppm}$ ) at the Darwin location. These results were not inferior to the OCO-2 retrieval results for the corresponding observation points. We also compared the $X_{\mathrm{CO} 2}$ retrievals with the normal $4 \mathrm{DV}$ ar method. The retrieval bias and standard deviation of $4 \mathrm{DV}$ ar method were bigger than NARA and OCO-2 results. Besides, the computational time consumed by one iteration from NARA was the least.

At present, the NARA algorithm is demonstrated effective, but still needs further improvements. The daily standard deviations of NARA $X_{\mathrm{CO} 2}$ retrievals were relatively large, especially over the ocean. In future work, we intend to further optimize the NARA algorithm, such as improving the prior state vector and generation of the initial ensemble, to enhance its robustness. Moreover, the algorithm was tested at several TCCON stations, next it will be tested through all TCCON stations to evaluate the retrieval results of target-, nadir-, and glint-mode observations. In addition, we plan to construct and incorporate data filtering and bias correction components customized to the NARA algorithm,

\section{REFERENCES}

Baker, D. F., Bösch, H., Doney, S. C., O’Brien, D., and Schimel, D. S. (2010). Carbon Source/sink Information provided by Column $\mathrm{CO}_{2}$ Measurements from the Orbiting Carbon Observatory. Atmos. Chem. Phys. 10 (9), 4145-4165. doi:10.5194/acp-10-4145-2010

Boesch, H., Baker, D., Connor, B., Crisp, D., and Miller, C. (2011). Global Characterization of $\mathrm{CO}_{2}$ Column Retrievals from Shortwave-Infrared Satellite Observations of the Orbiting Carbon Observatory-2 Mission. Remote Sensing. 3 (2), 270-304. doi:10.3390/rs3020270

Buchwitz, M., de Beek, R., Noël, S., Burrows, J. P., Bovensmann, H., Bremer, H., et al. (2005). Carbon Monoxide, Methane and Carbon Dioxide Columns Retrieved from SCIAMACHY by WFM-DOAS: Year 2003 Initial Data Set. Atmos. Chem. Phys. 5 (12), 3313-3329. doi:10.5194/acp-5-3313-2005

Buchwitz, M., Rozanov, V. V., and Burrows, J. P. (2000). A Near-Infrared Optimized DOAS Method for the Fast Global Retrieval of Atmospheric $\mathrm{CH}_{4}, \mathrm{CO}, \mathrm{CO}_{2}, \mathrm{H}_{2} \mathrm{O}$, and $\mathrm{N}_{2} \mathrm{O}$ Total Column Amounts from SCIAMACHY Envisat-1 Nadir Radiances. J. Geophys. Res. 105 (D12), 15231-15245. doi:10.1029/2000jd900191

Butz, A., Galli, A., Hasekamp, O., Landgraf, J., Tol, P., and Aben, I. (2012). TROPOMI Aboard Sentinel-5 Precursor: Prospective Performance of $\mathrm{CH}_{4}$ Retrievals for Aerosol and Cirrus Loaded Atmospheres. Remote Sensing Environ. 120, 267-276. doi:10.1016/j.rse.2011.05.030

Butz, A., Guerlet, S., Hasekamp, O., Schepers, D., Galli, A., Aben, I., et al. (2011). Toward Accurate $\mathrm{CO}_{2}$ and $\mathrm{CH}_{4}$ observations from GOSAT. Geophys. Res. Lett. 38 (14), a-n. doi:10.1029/2011gl047888

Butz, A., Hasekamp, O. P., Frankenberg, C., and Aben, I. (2009). Retrievals of Atmospheric $\mathrm{CO}_{2}$ from Simulated Space-Borne Measurements of Backscattered Near-Infrared Sunlight: Accounting for Aerosol Effects. Appl. Opt. 48 (18), 3322-3336. doi:10.1364/ao.48.003322

Chédin, A., Serrar, S., Scott, N. A., Crevoisier, C., and Armante, R. (2003). First Global Measurement of Midtropospheric $\mathrm{CO}_{2}$ from NOAA Polar Satellites: Tropical Zone. J. Geophys. Res. 108 (D18), 4581. doi:10.1029/2003jd003439 and make the algorithm become an operation procedure to produce mature $X_{\mathrm{CO} 2}$ products.

\section{DATA AVAILABILITY STATEMENT}

The raw data supporting the conclusions of this article will be made available by the authors, without undue reservation.

\section{AUTHOR CONTRIBUTIONS}

ZJ: Software, Validation, Formal analysis, Investigation, Data Curation, Writing-Original Draft, Visualization XT: Conceptualization, Methodology, Resources, Writing-Review and Editing, Supervision, Funding acquisition DM: Methodology, Writing-Review and Editing, Supervision HR: Software, Investigation, WritingReview and Editing.

\section{FUNDING}

This work was supported by the National Key Research and Development Program of China (2016YFA0600203), the National Natural Science Foundation of China (41575100), and the Key Research Program of Frontier Sciences, Chinese Academy of Sciences (CAS) (QYZDYSSW-DQC012).

Cogan, A. J., Boesch, H., Parker, R. J., Feng, L., Palmer, P. I., Blavier, J.-F. L., et al. (2012). Atmospheric Carbon Dioxide Retrieved from the Greenhouse Gases Observing SATellite (GOSAT): Comparison with Ground-Based TCCON Observations and GEOS-Chem Model Calculations. J. Geophys. Res. 117 (21), a-n. doi:10.1029/2012jd018087

Connor, B. J., Boesch, H., Toon, G., Sen, B., Miller, C., and Crisp, D. (2008). Orbiting Carbon Observatory: Inverse Method and Prospective Error Analysis. J. Geophys. Res. 113 (D5), a-n. doi:10.1029/2006jd008336

Cox, P. M., Betts, R. A., Jones, C. D., Spall, S. A., and Totterdell, I. J. (2000). Acceleration of Global Warming Due to Carbon-Cycle Feedbacks in a Coupled Climate Model. Nature. 408 (6809), 184-187. doi:10.1038/35041539

Crevoisier, C., Chédin, A., Matsueda, H., Machida, T., Armante, R., and Scott, N. A. (2009). First Year of Upper Tropospheric Integrated Content of $\mathrm{CO}_{2}$ from IASI Hyperspectral Infrared Observations. Atmos. Chem. Phys. 9 (14), 4797-4810. doi:10.5194/acp-9-4797-2009

Crisp, D., Atlas, R. M., Breon, F.-M., Brown, L. R., Burrows, J. P., Ciais, P., et al. (2004). The Orbiting Carbon Observatory (OCO) mission. Adv. Space Res. 34 (4), 700-709. doi:10.1016/j.asr.2003.08.062

Crisp, D., Fisher, B. M., O’Dell, C., Frankenberg, C., Basilio, R., Bösch, H., et al. (2012). The ACOS $\mathrm{CO}_{2}$ Retrieval Algorithm - Part II: Global $\mathrm{XCO}_{2}$ Data Characterization. Atmos. Meas. Tech. 5 (4), 687-707. doi:10.5194/amt-5-6872012

Crisp, D., Pollock, H. R., Rosenberg, R., Chapsky, L., Lee, R. A. M., Oyafuso, F. A., et al. (2017). The On-Orbit Performance of the Orbiting Carbon Observatory-2 (OCO-2) Instrument and its Radiometrically Calibrated Products. Atmos. Meas. Tech. 10 (1), 59-81. doi:10.5194/amt-10-59-2017

Dennis, J. E., Jr., and Schnabel, R. B. (1996). Numerical Methods for Unconstrained Optimization and Nonlinear Equations. Philadelphia, PA, USA: Society for Industrial and Applied Mathematics. doi:10.1137/1.9781611971200

Dilling, L., Doney, S. C., Edmonds, J., Gurney, K. R., Harriss, R., Schimel, D., et al. (2003). Therole Ofcarboncycleobservations Andknowledge Incarbonmanagement. Annu. Rev. Environ. Resour. 28, 521-558. doi:10.1146/annurev.energy.28.011503.163443

Eldering, A., Taylor, T. E., O’Dell, C. W., and Pavlick, R. (2019). The OCO-3 mission: Measurement Objectives and Expected Performance Based on 
1 Year of Simulated Data. Atmos. Meas. Tech. 12 (4), 2341-2370. doi:10.5194/amt-12-2341-2019

Evensen, G. (2009). Data Assimilation: The Ensemble Kalman Filter. Berlin Heidelberg: Springer-Verlag. doi:10.1007/978-3-642-03711-5

Griffith, D. W. T., Deutscher, N. M., Velazco, V. A., Wennberg, P. O., Yavin, Y., Keppel-Aleks, G., et al. (2014). TCCON Data from Darwin (AU). Anmeyondo, South Korea, Release GGG2014R0, TCCON data archive: CaltechDATA

Guerlet, S., Butz, A., Schepers, D., Basu, S., Hasekamp, O. P., Kuze, A., et al. (2013). Impact of Aerosol and Thin Cirrus on Retrieving and Validating $\mathrm{XCO}_{2}$ from GOSAT Shortwave Infrared Measurements. J. Geophys. Res. Atmos. 118 (10), 4887-4905. doi:10.1002/jgrd.50332

Han, R., and Tian, X. (2019). A Dual-Pass Carbon Cycle Data Assimilation System to Estimate Surface $\mathrm{CO}_{2}$ Fluxes and 3D Atmospheric $\mathrm{CO}_{2}$ Concentrations from Spaceborne Measurements of Atmospheric $\mathrm{CO}_{2}$. Geoscientific Model. Develop. Discussion Rev. doi:10.5194/gmd-2019-54

Hasekamp, O. P., and Butz, A. (2008). Efficient Calculation of Intensity and Polarization Spectra in Vertically Inhomogeneous Scattering and Absorbing Atmospheres. J. Geophys. Res. 113 (D20), D20309. doi:10.1029/2008JD010379

Hoinka, K. P. (1998). Statistics of the Global Tropopause Pressure. Mon. Wea. Rev. 126, 3303-3325. doi:10.1175/1520-0493(1998)126<3303:SOTGTP>2.0.CO;2

Hönninger, G., von Friedeburg, C., and Platt, U. (2004). Multi axis Differential Optical Absorption Spectroscopy (MAX-DOAS). Atmos. Chem. Phys. 4, 231-254. doi:10.5194/acp-4-231-2004

Jiang, X., and Yung, Y. L. (2019). Global Patterns of Carbon Dioxide Variability from Satellite Observations. Annu. Rev. Earth Planet. Sci. 47, 225-245. doi:10.1146/annurev-earth-053018-060447

Kulawik, S. S., Jones, D. B. A., Nassar, R., Irion, F. W., Worden, J. R., Bowman, K. W., et al. (2010). Characterization of Tropospheric Emission Spectrometer (TES) $\mathrm{CO}_{2}$ for Carbon Cycle Science. Atmos. Chem. Phys. 10 (12), 5601-5623. doi:10.5194/acp-10-5601-2010

Le Quéré, C., Andrew, R. M., Canadell, J. G., Sitch, S., Ivar Korsbakken, J., Peters, G. P., et al. (2016). Global Carbon Budget 2016. Earth Syst. Sci. Data 8 (2), 605-649. doi:10.5194/essd-8-605-2016

Miller, C. E., Crisp, D., DeCola, P. L., Olsen, S. C., Randerson, J. T., Michalak, A. M., et al. (2007). Precision Requirements for Space-Based Data. J. Geophys. Res. 112 (D10), D10314. doi:10.1029/2006jd007659

Nakajima, M., Kuze, A., and Suto, H. (2012). The Current Status of GOSAT and the Concept of GOSAT-2. In Sensors, Systems, and Next-Generation Satellites XVI. Edinburgh, United Kingdom: Society of Photo-Optical Instrumentation Engineers, 853306

O’Dell, C. W., Connor, B., Bösch, H., O’Brien, D., Frankenberg, C., Castano, R., et al. (2012). The ACOS $\mathrm{CO}_{2}$ Retrieval Algorithm - Part 1: Description and Validation against Synthetic Observations. Atmos. Meas. Tech. 5 (1), 99-121. doi:10.5194/amt-5-99-2012

O’Dell, C. W., Eldering, A., Wennberg, P. O., Crisp, D., Gunson, M. R., Fisher, B., et al. (2018). Improved Retrievals of Carbon Dioxide from Orbiting Carbon Observatory-2 with the Version 8 ACOS Algorithm. Atmos. Meas. Tech. 11 (12), 6539-6576. doi:10.5194/amt-11-6539-2018

Rayner, P. J., and O'Brien, D. M. (2001). The Utility of Remotely Sensed $\mathrm{CO}_{2}$ concentration Data in Surface Source Inversions. Geophys. Res. Lett. 28 (1), 175-178. doi:10.1029/2000gl011912

Reuter, M., Bösch, H., Bovensmann, H., Bril, A., Buchwitz, M., Butz, A., et al. (2013). A Joint Effort to Deliver Satellite Retrieved Atmospheric $\mathrm{CO}_{2}$ Concentrations for Surface Flux Inversions: the Ensemble Median Algorithm EMMA. Atmos. Chem. Phys. 13 (4), 1771-1780. doi:10.5194/acp13-1771-2013

Reuter, M., Bovensmann, H., Buchwitz, M., Burrows, J. P., Connor, B. J., Deutscher, N. M., et al. (2011). Retrieval of Atmospheric $\mathrm{CO}_{2}$ with Enhanced Accuracy and Precision from SCIAMACHY: Validation with FTS Measurements and Comparison with Model Results. J. Geophys. Res. 116 (D4), D04301. doi:10.1029/2010jd015047

Reuter, M., Buchwitz, M., Schneising, O., Heymann, J., Bovensmann, H., and Burrows, J. P. (2010). A Method for Improved SCIAMACHY $\mathrm{CO}_{2}$ Retrieval in the Presence of Optically Thin Clouds. Atmos. Meas. Tech. 3 (1), 209-232. doi:10.5194/amt-3-209-2010

Schneising, O., Bergamaschi, P., Bovensmann, H., Buchwitz, M., Burrows, J. P., Deutscher, N. M., et al. (2012). Atmospheric Greenhouse Gases Retrieved from
SCIAMACHY: Comparison to Ground-Based FTS Measurements and Model Results. Atmos. Chem. Phys. 12 (3), 1527-1540. doi:10.5194/acp-12-1527-2012 Spurr, R. J. D., Kurosu, T. P., and Chance, K. V. (2001). A Linearized Discrete Ordinate Radiative Transfer Model for Atmospheric Remote-Sensing Retrieval. J. Quantitative Spectrosc. Radiative Transfer 68 (6), 689-735. doi:10.1016/ S0022-4073(00)00055-8

Spurr, R., and Natraj, V. (2011). A Linearized Two-Stream Radiative Transfer Code for Fast Approximation of Multiple-Scatter fields. J. Quantitative Spectrosc. Radiative Transfer. 112 (16), 2630-2637. doi:10.1016/j.jqsrt.2011.06.014

Taylor, T. E., O’Dell, C. W., Frankenberg, C., Partain, P. T., Cronk, H. Q., Savtchenko, A., et al. (2016). Orbiting Carbon Observatory-2 $\left(\mathrm{OCO}_{2}\right)$ Cloud Screening Algorithms: Validation against Collocated MODIS and CALIOP Data. Atmos. Meas. Tech. 9 (3), 973-989. doi:10.5194/amt-9-973-2016

Tian, X., Xie, Z., Liu, Y., Cai, Z., Fu, Y., Zhang, H., et al. (2014a). A Joint Data Assimilation System (Tan-Tracker) to Simultaneously Estimate Surface $\mathrm{CO}_{2}$ Fluxes and 3-D Atmospheric $\mathrm{CO}_{2}$ Concentrations from Observations. Atmos. Chem. Phys. 14 (23), 13281-13293. doi:10.5194/acp-14-13281-2014

Tian, X., Xie, Z., Cai, Z., Liu, Y., Fu, Y., and Zhang, H. (2014b). The Chinese Carbon Cycle Data-Assimilation System (Tan-Tracker). Chinese Sci. Bull. 59 (14), 1541-1546. doi:10.1007/s11434-014-0238-1

Tian, X., and Feng, X. (2015). A Non-linear Least Squares Enhanced POD-4DVar Algorithm for Data Assimilation. Tellus A: Dynamic Meteorology and Oceanography. 67 (1), 25340. doi:10.3402/tellusa.v67.25340

Tian, X., Zhang, H., Feng, X., and Xie, Y. (2018). Nonlinear Least Squares En4DVar to 4DEnVar Methods for Data Assimilation: Formulation, Analysis, and Preliminary Evaluation. Monthly Weather Rev. 146 (1), 77-93. doi:10.1175/mwr-d-17-0050.1

Wennberg, P. O., Wunch, D., Roehl, C. M., Blavier, J.-F., Toon, G. C., and Allen, N. T. (2016). TCCON Data from Lamont (US). (GGG2014R1, TCCON data archive: CaltechDATA)

Wu, L., Hasekamp, O., Hu, H., Landgraf, J., Butz, A., aan de Brugh, J., et al. (2018). Carbon Dioxide Retrieval from OCO-2 Satellite Observations Using the RemoTeC Algorithm and Validation with TCCON Measurements. Atmos. Meas. Tech. 11 (5), 3111-3130. doi:10.5194/amt-11-3111-2018

Wunch, D., Toon, G. C., Blavier, J. F. L., Washenfelder, R. A., Notholt, J., Connor, B. J., et al. (2011). The Total Carbon Column Observing Network. Phil. Trans. R. Soc. A. 369, 2087-2112. doi:10.1098/rsta.2010.0240

Wunch, D., Wennberg, P. O., Osterman, G., Fisher, B., Naylor, B., Roehl, C. M., et al. (2017). Comparisons of the Orbiting Carbon Observatory-2 (OCO-2) $\mathrm{XCO}_{2}$ Measurements with TCCON. Atmos. Meas. Tech. 10 (6), 2209-2238. doi:10.5194/amt-10-2209-2017

Yang, D., Liu, Y., Cai, Z., Chen, X., Yao, L., and Lu, D. (2018). First Global Carbon Dioxide Maps Produced from TanSat Measurements. Adv. Atmos. Sci. 35 (6), 621-623. doi:10.1007/s00376-018-7312-6

Yokota, T., Yoshida, Y., Eguchi, N., Ota, Y., Tanaka, T., Watanabe, H., et al. (2009). Global Concentrations of $\mathrm{CO}_{2}$ and $\mathrm{CH}_{2}$ Retrieved from GOSAT: First Preliminary Results. Sola. 5 (1), 160-163. doi:10.2151/sola.2009-04110.2151/sola.2009-041

Yoshida, Y., Ota, Y., Eguchi, N., Kikuchi, N., Nobuta, K., Tran, H., et al. (2011). Retrieval Algorithm for $\mathrm{CO}_{2}$ and $\mathrm{CH}_{2}$ Column Abundances from Short-Wavelength Infrared Spectral Observations by the Greenhouse Gases Observing Satellite. Atmos. Meas. Tech. 4 (4), 717-734. doi:10.5194/amt-4-717-2011

Yue, T., Zhang, L., Zhao, M., Wang, Y., and Wilson, J. (2016). Space- and GroundBased $\mathrm{CO}_{2}$ Measurements: A Review. Sci. China Earth Sci. 59 (11), 2089-2097. doi:10.1007/s11430-015-0239-7

Zhang, H. (2019). Improvement and Application of Nonlinear Least Squares Ensemble Four-Dimensional Variational Assimilation Method. Beijing, China: Institute of Atmospheric Physics, Chinese Academy of Sciences.

Conflict of Interest: The authors declare that the research was conducted in the absence of any commercial or financial relationships that could be construed as a potential conflict of interest.

Copyright (c) 2021 Jin, Tian, Duan and Han. This is an open-access article distributed under the terms of the Creative Commons Attribution License (CC BY). The use, distribution or reproduction in other forums is permitted, provided the original author(s) and the copyright owner(s) are credited and that the original publication in this journal is cited, in accordance with accepted academic practice. No use, distribution or reproduction is permitted which does not comply with these terms. 


\section{APPENDIX A}

The following mathematical derivation exhibits how the optimal state vector is obtained without calculating the weighting function matrix and its transposition.

The first-derivative matrix $J_{a c} Q(\boldsymbol{\beta})$ of $Q(\boldsymbol{\beta})$ can be computed as follows:

$$
J_{a c} Q(\boldsymbol{\beta})=\frac{\partial Q(\boldsymbol{\beta})}{\partial \boldsymbol{\beta}}=\left(\frac{\sqrt{N-1} \mathbf{I}}{S_{\varepsilon,+}^{-1 / 2} \mathbf{K} \mathbf{P}_{x}}\right),
$$

where I denote the $N \times N$ identity matrix. The Gauss-Newton iterative solution for the nonlinear least squares problem is defined by (Dennis and Schnabel 1996):

$$
\boldsymbol{\beta}^{i}=\boldsymbol{\beta}^{i-1}-\left\{\left[J_{a c} Q\left(\boldsymbol{\beta}^{i-1}\right)\right]^{\mathrm{T}} J_{a c} Q\left(\boldsymbol{\beta}^{i-1}\right)\right\}^{-1} \times\left[J_{a c} Q\left(\boldsymbol{\beta}^{i-1}\right)\right]^{\mathrm{T}} Q\left(\boldsymbol{\beta}^{i-1}\right) .
$$

Substituting Eqs. 10, A1 into Eq. A2, we obtain

$$
\begin{aligned}
{\left[(N-1) \mathbf{I}+\left(\mathbf{K} \mathbf{P}_{x}\right)^{\mathrm{T}} \mathbf{S}_{\varepsilon}^{-1}\right] \Delta \boldsymbol{\beta}^{i}=} & -\left\{\left(\mathbf{K P}_{x}\right)^{\mathrm{T}} \mathbf{S}_{\varepsilon}^{-1}\left[F^{\prime}\left(\mathbf{P}_{x} \boldsymbol{\beta}^{i-1}\right)-\boldsymbol{y}^{\prime}\right]\right. \\
& \left.+(N-1) \boldsymbol{\beta}^{i-1}\right\} .
\end{aligned}
$$

where $\Delta \boldsymbol{\beta}^{i}=\boldsymbol{\beta}^{i}-\boldsymbol{\beta}^{i-1}$. The linear system Eq. A3 can be solved using the conjugate gradient (CG) method or a preconditioned CG method. Since $\left(\mathbf{K P}_{x}\right)^{\mathrm{T}}$ can be obtained simply by transposing $\mathbf{K} \mathbf{P}_{x}$, the transposition of weighting function matrix is nicely avoided.

We substitute $\quad \mathbf{P}_{y}=\mathbf{K P}_{x} \quad$ and $\boldsymbol{\beta}^{i-1} \approx\left[\left(\mathbf{P}_{y}\right)^{\mathrm{T}}\left(\mathbf{P}_{y}\right)\right]^{-1}\left(\mathbf{P}_{y}\right)^{\mathrm{T}} \mathbf{K}\left(\mathbf{P}_{x} \boldsymbol{\beta}^{i-1}\right)$ into Eq. A3 and obtain:

$$
\Delta \boldsymbol{\beta}^{i}=\left(\mathbf{P}_{y}^{\#}\right)^{\mathrm{T}} \mathbf{S}_{\varepsilon}^{-1}\left[F^{\prime}\left(\mathbf{P}_{x} \boldsymbol{\beta}^{i-1}\right)-\boldsymbol{y}^{\prime}\right]+\left(\mathbf{P}_{y}^{*}\right)^{\mathrm{T}} \mathbf{K}\left(\mathbf{P}_{x} \boldsymbol{\beta}^{i-1}\right),
$$

where

$$
\left(\mathbf{P}_{y}^{\#}\right)^{\mathrm{T}}=-\left[\left(\mathbf{P}_{y}\right)^{\mathrm{T}} \mathbf{S}_{\varepsilon}^{-1}\left(\mathbf{P}_{y}\right)+(N-1) \mathbf{I}\right]^{-1}\left(\mathbf{P}_{y}\right)^{\mathrm{T}},
$$

and

$$
\begin{aligned}
\left(\mathbf{P}_{y}^{*}\right)^{\mathrm{T}}= & -(N-1)\left[\left(\mathbf{P}_{y}\right)^{\mathrm{T}} \mathbf{S}_{\varepsilon}^{-1}\left(\mathbf{P}_{y}\right)+(N-1) \mathbf{I}\right]^{-1} \\
& \times\left[\left(\mathbf{P}_{y}\right)^{\mathrm{T}}\left(\mathbf{P}_{y}\right)\right]^{-1}\left(\mathbf{P}_{y}\right)^{\mathrm{T}} .
\end{aligned}
$$

Here $\Delta \boldsymbol{\beta}^{i}$ can be computed explicitly by Eq. A4 and the CG iterations are thus avoided.

To further reduce the implementation complexity by abandoning the use of the weighting function matrix, we rewrite Eq. A4 into

$$
\Delta \boldsymbol{\beta}^{i}=\left(\mathbf{P}_{y}^{\#, a}\right)^{\mathrm{T}} \mathbf{S}_{\varepsilon}^{-1}\left[F^{\prime}\left(\mathbf{P}_{x} \boldsymbol{\beta}^{i-1}\right)-\boldsymbol{y}^{\prime}\right]+\left(\mathbf{P}_{y}^{*, a}\right)^{\mathrm{T}} F^{\prime}\left(\mathbf{P}_{x} \boldsymbol{\beta}^{i-1}\right),
$$

where

$$
\begin{aligned}
&\left(\mathbf{P}_{y}^{\#, a}\right)^{\mathrm{T}}=-\left[\left(\mathbf{P}_{y}^{a}\right)^{\mathrm{T}} \mathbf{S}_{\varepsilon}^{-1}\left(\mathbf{P}_{y}^{a}\right)+(N-1) \mathbf{I}\right]^{-1}\left(\mathbf{P}_{y}^{a}\right)^{\mathrm{T}}, \\
&\left(\mathbf{P}_{y}^{*, a}\right)^{\mathrm{T}}=-(N-1)\left[\left(\mathbf{P}_{y}^{a}\right)^{\mathrm{T}} \mathbf{S}_{\varepsilon}^{-1}\left(\mathbf{P}_{y}^{a}\right)+(N-1) \mathbf{I}\right]^{-1} \\
& \times\left[\left(\mathbf{P}_{y}^{a}\right)^{\mathrm{T}}\left(\mathbf{P}_{y}^{a}\right)\right]^{-1}\left(\mathbf{P}_{y}^{a}\right)^{\mathrm{T}}, \\
& \mathbf{P}_{y}^{a}=\left(\boldsymbol{y}_{1}^{\prime a}, \ldots, \boldsymbol{y}_{N}^{\prime a}\right),
\end{aligned}
$$

and

$$
\boldsymbol{y}_{j}^{\prime a}=F\left(\boldsymbol{x}^{i-1, *}+\boldsymbol{x}_{j}^{\prime}\right)-F\left(\boldsymbol{x}^{i-1, *}\right) .
$$

